\title{
A reconstruction of large-scale circulation in the Pacific Ocean north of $10^{\circ} \mathrm{N}$
}

\author{
M. I. Yaremchuk ${ }^{1}$ \\ International Pacific Research Center, University of Hawaii at Manoa, Honolulu
}

\begin{abstract}
A dynamically consistent steady state circulation pattern of the North Pacific (NP) ocean is presented. The fields describing oceanic state and atmospheric forcing are obtained by fitting a steady state large-scale circulation model to the 1.0 release of World Ocean Circulation Experiment hydrology, da Silva atmospheric climatologies, TOPEXPoseidon altimetry, and Marine Environmental Data Service drifter data. Heat, salt, and mass transports of the major circulation features of the NP are presented. All the estimates are supplied with error bars obtained via the approximate inversion of the Hessian matrix. The optimized pattern shows, in particular, that NP is heated at an average rate of $11 \pm 7$ $\mathrm{W} \mathrm{m}{ }^{-2}$ and loses $26 \pm 18 \mathrm{~cm}$ of fresh water from its surface per year. Zonal mean transport north of $20^{\circ} \mathrm{N}$ is characterized by an upwelling of $7 \pm 2 \mathrm{~Sv}\left(1 \mathrm{~Sv}=10^{6} \mathrm{~m}^{3} \mathrm{~s}^{-1}\right)$ in the intermediate layers $(500-3000 \mathrm{~m})$ within the latitudes $30^{\circ}-50^{\circ} \mathrm{N}$. A weaker overturning cell characterized by the downwelling of $3 \pm 1 \mathrm{~Sv}$ at $55^{\circ}-60^{\circ} \mathrm{N}$ contributes to the meridional circulation pattern north of $51^{\circ} \mathrm{N}$. The net meridional advective heat transport in the midlatitudes is statistically undistinguishable from zero and amounts to $-0.1 \pm 0.4 \mathrm{PW}$ (1 $\mathrm{PW}=10^{15} \mathrm{~W}$ ). At $35^{\circ} \mathrm{N}$, fresh water is transported southward at the rate equivalent to the average rainfall to the north of $35^{\circ} \mathrm{N}$ of $18 \pm 14 \mathrm{~cm} \mathrm{yr}^{-1}$. Analysis of the water mass transformation rates reveals the major NP intermediate water formation site to be east of Hokkaido and South Kuril Islands. A much weaker source is detected in the Alaskan Gyre. The net production rate of the NPIW source water east of Kuril Islands is estimated as $2.5 \mathrm{~Sv}$.
\end{abstract}

\section{Introduction}

The North Pacific (NP) is considered to be one of the most dynamically important regions of the world ocean. Expanded interest in studies of its circulation is due to the extremely powerful El Nino event of 1997-1998. In recent years most efforts to investigate the long-term changes of the Pacific Ocean state were primarily by the means of numerical modeling. State-of-the-art models with basin-scale resolutions higher than $1 / 6^{\circ}$ closely simulate the reality [e.g., Hurlburt et al., 1996]. Nevertheless, evaluating the sources of model-data discrepancies from such long-term runs, whether they are largely due to forcing errors or to model deficiencies, is hard. Such error estimates are especially important for climatological research and require thorough sensitivity analysis, which lies beyond the capabilities of the modern computers.

Inverse models are usually much coarser and somewhat simpler than sophisticated general circulation models (GCMs), but they provide an opportunity for more detailed error analysis and give us a tool for optimization of the unknown model parameters by minimizing model-data discrepancies. In recent years a number of studies focused on the inversion of climatological data into the coarse-resolution GCMs. Yu and Malanotte-Rizzoli [1998] assimilated Levitus and Boyer [1994] and Levitus et al. [1994] climatology in the North Atlantic. Lee and Marotzke [1997, 1998] combined Levitus [1982] hydrology with Hellerman and Rosenstein [1983] wind stress and Oberhuber [1988] surface fluxes to investigate large-scale variability in the

\footnotetext{
${ }^{1}$ Also at Shirshov Institute of Oceanology, Moscow, Russia.

Copyright 2001 by the American Geophysical Union.

Paper number 2000JC900108.

0148-0227/01/2000JC900108\$09.00
}

Indian Ocean. Another effort of the Massachusetts Institute of Technology (MIT) inverse modelers to adjust the $2^{\circ}$ global GCM to TOPEX/Poseidon altimetry is now underway [Stammer et al., 1997]. Neither of these studies has focused on the North Pacific Ocean.

In this paper we shall try to reconstruct the NP large-scale circulation by merging a variety of data sources obtained during the past decade. In recent years the NP circulation has been intensely investigated both by means of "direct" modeling and more traditional data analysis techniques. Reid [1997] utilized a modified version of the dynamical method to compute steady state currents in the Pacific Ocean from 5258 hydrographic stations. The works of Semtner and Chervin [1992] and Fujio et al. [1992] are based on GCM integrations on global scale. Both models were nudged to Levitus [1982] climatology and Hellerman and Rosenstein [1983] wind stress. Among the regional model studies incorporating various data, Hurlburt et al. [1996] investigated the Kuroshio-Oyashio current system and NP circulation using model configurations with up to $1 / 16^{\circ}$ resolution; Holloway et al. [1995] focused on the Sea of Japan; and Overland et al. [1994] studied circulation in the Bering Sea.

Inverse modeling papers that deal with the NP are few and either employ too coarse a resolution if applied to the whole NP basin [e.g., Fukasawa et al., 1992] or deal with smaller basins [Brasseur, 1991; Grotov et al., 1998].

The contribution of the present study should be placed between the results of high-resolution direct computations and the output of lower-resolution inverse models. Compared to recent data analysis by means of inverse GCMs, a larger diversity of data is utilized in the present study. The additional data include drifter velocities and transports through some passages like Bering Strait. The underlying model features the basic physics present in GCMs, except for nonlinear terms in 


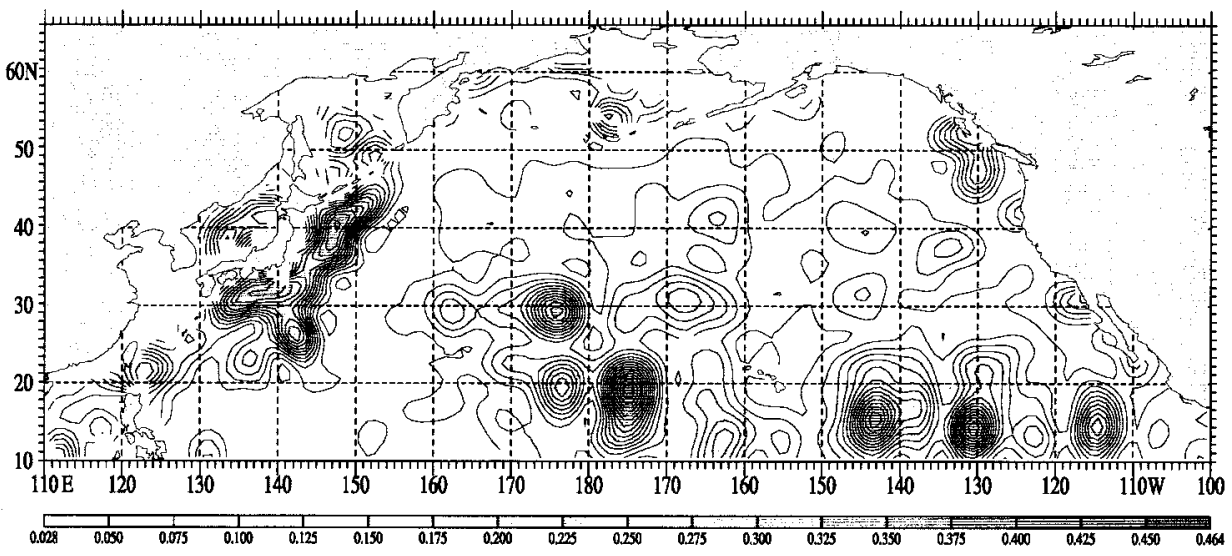

Figure 1. Typical error contours of the WOCE data set (potential temperature, $600 \mathrm{~m}$ ). The errors are normalized by $1.5^{\circ} \mathrm{C}$, which is the rms variation of temperature at that level.

the momentum equation, and has a moderate $1^{\circ}$ resolution in the horizontal and a refined grid with 43 layers in the vertical. In contrast to the climatological inversions performed for the Indian and Atlantic Oceans, which utilized the Levitus and Boyer [1994] and Levitus et al. [1994] hydrography, the 1998 release of World Ocean Circulation Experiment (WOCE) climatology has been used. The present study is focused on the retrieval of the steady state large-scale circulation and does not feature any time dependence, unlike recent GCM inversions. On the other hand, the much smaller computational cost of the assimilation scheme enabled us to conduct more complete sensitivity and error analyses. All the major results are supplied with error bars, estimated through the expansion of the inverse square root of the Hessian matrix in Chebyshev polynomials.

The paper is organized as follows: section 2 describes data and prior error bars. Section 3 outlines the model, the assimilation algorithm, and the posterior error estimation scheme. Section 4 presents quantitative estimates of the North Pacific Ocean circulation features, which include the description of overturning circulation, heat, and fresh water fluxes and a brief analysis of the transformation rates between the major water masses. Section 5 presents a summary and conclusions.

\section{Data}

Four physically different types of data were used in the analysis.

1. Climatological fields of the potential temperature and salinity were compiled from the WOCE data set at the Special Analysis Center in Hamburg [e.g., Gouretski and Jancke, 1999] (see also www.dkrz.de/u241046/SACserver). The data set is a result of joint reanalysis of the 1994 Levitus hydrology and WOCE hydrographic data that were obtained during 19901997 and the data from a number of recent high-quality nonWOCE cruises. The major difference between these data and the existing climatologies is the technique of optimal interpolation. Objective analysis has been performed on neutral surfaces, thus avoiding production of artificial water masses and allowing for more consistency with large-scale dynamics. The WOCE climatology has somewhat better resolution in the vertical (43 levels versus 33 in the Levitus data set).

Spatial distribution of the reanalysis error magnitudes that were used in the computation can be found at the Web site of Hamburg SAC. In general, the error level for temperature and salinity fields varies within $0.05-0.10$ if the errors are normalized by the horizontal rms variations of the fields. In deep layers the average error level increases to $0.15-0.25$, possibly owing to the much weaker $\mathrm{S} / \mathrm{N}$ ratio of the underlying measurements. Additionally, hydrographic errors were assumed to increase substantially in the regions of higher mesoscale variability such as Kuroshio extension and Oyashio. In these areas, relative errors varied in the range of $0.15-0.35$ (Figure 1).

2. Climatological fluxes of heat, freshwater, and momentum were compiled at the ocean surface from da Silva [1995] climatology. The data were taken from the Web site ingrid. ldgo.columbia.edu:81/-SOURCES/.DASILVA. Several data sets were compiled using the $1^{\circ}$ climatology and anomalies for the period between 1960 and 1994. The mean states, obtained by averaging the anomalies for various periods, exhibited rms spatial variability close to $20-30 \%$ of that of the climatology, but the main qualitative features of the pattern (Plate 1) did not change drastically. In the analysis we assumed that relative uncertainties in the ocean-atmosphere fluxes are close to $30 \%$ of their spatial variability (i.e., $25 \mathrm{~W} \mathrm{~m}^{-2}, 32 \mathrm{~cm} \mathrm{yr}^{-1}$, and 0.2 dyn $\mathrm{cm}^{-1}$ for heat, freshwater, and momentum fluxes, respectively) and utilized the $1^{\circ}$ da Silva et al. [1995] climatology as a basic data set for optimization. These values are almost 2 times smaller than those used by Lee and Marotzke [1997] in their GCM-based inversion of Oberhuber [1988] climatologies in the Indian Ocean.

3. Sea surface height (SSH) data were extracted from the TOPEX/Poseidon database of the University of Texas (ftp. csr.utexas.edu/sst.html). The 5 year mean has been computed by adding the averaged gridded anomalies for the period 19921997 to the mean $1^{\circ} \mathrm{SSH}$. The resultant climatological field represents the 5 year mean SSH relative to the Joint Gravity Model (JGM-3) geoid and has an estimated accuracy of $20 \mathrm{~cm}$, a result due almost entirely to residual errors in the geoid model (ftp.csr.utexas.edu/sst.html). In the computations we adopted this error level for altimetry assuming its spatial homogeneity. It should be noted that this treatment of SSH error is somewhat approximative because it does not take explicitly into the account the dependence of JGM-3 errors on spatial scales (spherical harmonic numbers).

4. Surface current velocities were determined from the trajectories of 3885 Drifting Buoy Data Assembly Center (www. aoml.noaa.gov/phod/dac) surface drifters that moved through the model domain between January 1990 and December 1996. Most of the drifters were drogued between 5 and $15 \mathrm{~m}$ and therefore sample the velocity in the surface Ekman layer. The 


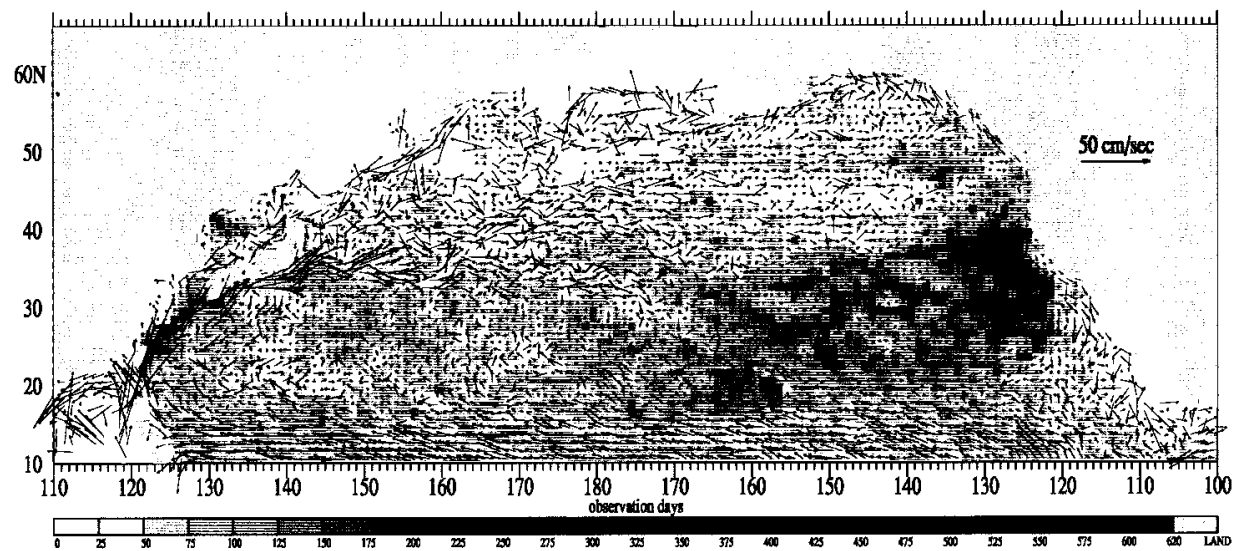

Figure 2. Mean upper layer velocities derived from drifter data. The shaded panel gives the total time spent by drifters in each $1^{\circ}$ grid cell.

total number of position fixes was $3,116,948$, the number of drifter years was 1018.3, and the average time $\bar{t}$ spent by drifters in a typical model grid cell was 72 days (Figure 2). Differences in consecutive positions were used to estimate velocity. Drifter positions were equidistant in time with a 6 hour separation. Outliers were defined by speeds exceeding $1.5 \mathrm{~m} \mathrm{~s}^{-1}$, and they were discarded prior to the calculation of the mean velocity for each model grid cell. Statistical analysis of the estimated mean velocity field has shown that the velocity error within a grid cell could be well approximated by a simple relationship between $\sigma(v)$ and the total time $t$ spent by drifters in that cell:

$$
\sigma(v)=\overline{(v-\bar{v})^{2}}=1 \mathrm{~m}^{2} \mathrm{~s}^{-2} \cdot\left(\frac{9 \text { days }}{t}\right)^{2}
$$

This formula was obtained by fitting the dependence of $\sigma(v)$ on $t$ with quadratic hyperbola. As it can be seen from Figure 2, the sampling time for a grid cell generally varies within 50-150 days and rarely exceeds 1 year. An assumption was made that $\bar{v}$ samples the "steady state" velocity field at a given cell with an rms error $\sigma(v)$.

5. The total mass transport is estimated across four vertical sections $L_{\alpha}, \alpha=1, \ldots, 4$ of the computational domain shown in Plate 2. The estimates were extracted from the oceanographic literature published between 1991 and 1998 [e.g., Sekine and Kutsuwada, 1994; Lukas et al., 1991; Cokelet and Schall, 1996; Wu et al., 1995]. The following values for the transports $F_{\alpha}^{*}$ and their uncertainties were adopted: Kuroshio at $144^{\circ} \mathrm{E}$ is $58 \pm 14 \mathrm{~Sv}$, Mindanao Current at $10^{\circ} \mathrm{N}$ is $15 \pm 6 \mathrm{~Sv}$, Bering Strait transport is $1 \pm 0.5 \mathrm{~Sv}$, and North Equatorial Current at the dateline is $20 \pm 8 \mathrm{~Sv}$.

\section{Interpolation Scheme}

\subsection{Statistical Hypothesis}

The above mentioned five types of data were merged together in a dynamically consistent manner using the variational data assimilation technique [e.g., Thacker and Long, 1988]. The ocean state was reconstructed on a regular grid with $1^{\circ}$ horizontal resolution. In the vertical the grid has 43 points with separation from $10 \mathrm{~m}$ in the upper layers to $250 \mathrm{~m}$ in the deep ocean. The variational interpolation algorithm is basically the same as that used by Grotov et al. [1998] for the reconstruction of the ocean state in the coastal seas of the Southern Pacific
Ocean. The interpolated fields satisfy a number of dynamical relationships, including geostrophy, hydrostatics, continuity, and a nonlinear equation of state for seawater. Additionally, advective-diffusive tracer balances are assumed to be in steady state. The major difference with the constraints used by Grotov et al. [1998] is in the more general form of the dynamical equations, which now incorporate a relationship for potential temperature, a relationship for salinity, and the nonlinear equation for the seawater state (see Appendix A).

To obtain the interpolation pattern, we assume that climatological data sample a set of random Gaussian fields with unknown means whose variances are due to random errors generally induced by motions at scales smaller than $1^{\circ}$. The prior probability density function is proportional to exp $(-\mathfrak{I})$, where the argument $\mathfrak{I}$ of the Gaussian exponent has the form of the following quadratic cost function:

$$
\begin{aligned}
\mathfrak{I}= & \int_{\Omega}\left[W_{\theta}\left(\theta-\theta^{*}\right)^{2}+W_{S}\left(S-S^{*}\right)^{2}\right] d \Omega \\
& +\int_{z=0}\left[W_{\theta}^{B}\left(B_{\theta}-B_{\theta}^{*}\right)^{2}+W_{S}^{B}\left(B_{S}-B_{S}^{*}\right)^{2}+W_{\zeta}\left(\zeta-\zeta^{*}\right)^{2}\right. \\
& \left.+\mathbf{W}_{\mathbf{u}}\left(\mathbf{u}-\mathbf{u}^{*}\right)^{2}+W_{\tau}\left(\boldsymbol{\tau}-\boldsymbol{\tau}^{*}\right)^{2}\right] d \omega \\
& +\sum_{\alpha=1}^{4} W_{\alpha}\left[\int_{L_{\alpha}}\left(\mathbf{u} d \mathbf{n}_{\alpha}\right)-F_{\alpha}^{*}\right]^{2} \\
& +\int_{\Omega}\left[W_{S}^{s}(\Delta S)^{2}+W_{\theta}^{s}(\Delta \theta)^{2}\right] d \Omega \\
& +\int_{z=0}\left[W_{B_{\theta}}^{s}\left(\Delta B_{\theta}\right)^{2}+W_{B_{S}}^{s}\left(\Delta B_{S}\right)^{2}+W_{\zeta}^{s}(\Delta \zeta)^{2}+W_{\tau}^{s}(\Delta \boldsymbol{\tau})^{2}\right. \\
& \left.+\mathbf{W}_{\psi}^{s}\left(\Delta \int_{-H}^{0} \mathbf{u} d z\right)^{2}\right] d \omega+W_{w}\left(F_{z=-H}^{w}\right)^{2} d \omega \\
& +\int_{\Omega}\left[W_{\theta}^{t}\left(F_{\theta}^{e}\right)^{2}+W_{S}^{t}\left(F_{S}^{e}\right)^{2}\right] d \Omega \\
& +W_{\theta}^{e}\left(\int_{\Omega_{\varphi}}\left[F_{\theta}^{e} d \Omega\right)^{2}+W_{S}^{e}\left(\int_{\Omega_{\varphi}} F_{S}^{e} d \Omega\right)^{2} d \varphi\right.
\end{aligned}
$$


Three groups of terms constitute the cost function. The first eight terms penalize differences between the interpolated (model) fields and the data components denoted by asterisks. Inverse variances $W_{\varphi}$ of the error fields of the potential temperature $\theta$, salinity $S$, sea surface elevation $\zeta$, wind stress $\tau$, ocean-atmosphere fluxes $B_{\theta}$ and $B_{S}$, and total transports across the four sections $L_{\alpha}$ (Plate 2) were outlined in section 2 , and $d \Omega, d \omega$, and $d \mathbf{n}_{\alpha}$ stand for the elements of the ocean volume, its surface, and the surfaces of vertical sections $L_{\alpha}$ multiplied by the unit vectors normal to those surfaces.

The second group of terms enforce smoothness in the fields of $\theta, S, B_{\theta}, B_{S}, \zeta$, and $\tau$ and the vector of total transport. Smoothness is enforced by penalizing horizontal Laplacians $\Delta$ of the model fields. Prior variances $\left(W^{s}\right)^{-1}$ were estimated as the mean squared amplitudes of the corresponding Laplacians of the first-guess solution.

The last group of five terms contains the error fields $F_{\theta}^{e}, F_{S}^{e}$, and $F^{w}$ and penalizes residuals in the steady state advectiondiffusion balances for temperature (salinity) and the uncertainty in the Ekman pumping rate into the bottom boundary layer (BBL; see Appendix A). The prior estimate of the variance in mass exchange with the unresolved BBL was set to $1.5 \mathrm{~m} \mathrm{yr}^{-1}$. This value was derived from a simple estimate of the BBL Ekman pumping rate induced by large-scale abyssal currents: $w \sim 1 / f \operatorname{curl}\left(\nu \mathbf{u}_{z}\right) \sim \nu U / f h L$. Here $\nu=1 \mathrm{~cm}^{2} \mathrm{~s}^{-1}$ is the BBL vertical momentum diffusion, $f=10^{-4} \mathrm{~s}^{-1}$ is the Coriolis parameter, $h=\sqrt{\nu / f}$ is the BBL thickness, $U=1 \mathrm{~cm}$ $\mathrm{s}^{-1}$ is the typical magnitude of the bottom current, and $L=$ $200 \mathrm{~km}$ is its typical horizontal scale.

Statistics of the residuals $F_{\theta}^{e}$ and $F_{S}^{e}$ in the advectiondiffusion balance equation are defined by the two groups of terms. The first two terms are proportional to $W_{\theta}^{t}$ and $W_{S}^{t}$ and introduce prior knowledge of the magnitude of these residuals. Simple analysis of the $\theta / S$ balance equations shows that for temporal scales $T^{*}$ of several years and spatial scales $L$ larger than $300 \mathrm{~km}$, temporal derivatives and diffusion are $U T^{*} / L \sim$ 100 times smaller than the typical values of the advective balance terms. Therefore the residuals were constrained to vary within the limits of $\sigma(\theta) / T^{*}$ and $\sigma(S) / T^{*}$ by setting the weights $W_{\theta}^{t}$ and $W_{S}^{t}$ inversely proportional to the horizontal variances of potential temperature $\sigma^{2}(\theta)$ and salinity $\sigma^{2}(S)$ divided by $T^{*}$ squared. Such a rough assumption on the statistics of $F_{\theta}^{e}$ and $F_{S}^{e}$ is good enough for studies of the general features of circulation, which are heavily constrained by the data. Caution must be exercised, however, if we are going to study more delicate things like the net meridional fluxes of heat and salt or zonally averaged overturning circulation. Estimation of these quantities involves basin-scale integration of the "stable" features that tend to cancel each other. Therefore the impact of relatively small residuals on those integral quantities may be large. For instance, the random variable obtained as the basin integral of the Gaussian $\delta$-correlated field $F_{\theta}^{e}$ will vary around its zero mean with an amplitude of $\sim 0.07^{\circ} \mathrm{C} \mathrm{km}^{3}$ $\mathrm{s}^{-1}$ or $0.3 \mathrm{PW}$, which is comparable with the net meridional NP advective heat fluxes found in literature. To eliminate this influence of the residual fields on the integral balances, an additional assumption concerning their statistics has been made by introducing the terms proportional to $W_{\theta}^{e}(\varphi)$ and $W_{S}^{e}(\varphi)$. The weighting functions $W_{\theta}^{e}$ and $W_{S}^{e}$ have the sense of prior inverse variances of the integrals of $F_{\theta, S}^{e}$ taken over the NP subdomains $\Omega_{\varphi}$ bounded by the latitude $\varphi$ at the south and the Bering Strait at the north. The magnitudes of $W_{\theta}^{e}$ and $W_{S}^{e}$ were set to constrain these basin-scale integrals of the residuals to vary within the limits of $0.05 \mathrm{PW}$ and $0.03 \mathrm{~Sv}$ for temperature and fresh water, respectively, in correspondence with the typical magnitude of the integral diffusive fluxes available from the first-guess solution and eddy fluxes available from the highresolution GCM runs [e.g., Semtner and Chervin, 1992].

The optimal interpolation pattern was obtained by minimization of the $\mathfrak{I}$ subject to the dynamical constraints. The cost function was optimized by varying the set of control fields $\{\theta$, $\left.S, \zeta, \tau, B_{\theta}, B_{S}\right\}$ whose values entirely define the ocean state. With the resolution of 43 layers in the vertical, the control vector dimension was $D=434,602$. The minimization started from the first-guess solution, which was the result of the velocity field diagnosis, based on application of the dynamical method to climatological data. At this stage, imbalances in the steady state $\theta$ and $S$ transport equations, the bottom boundary condition for the vertical velocity, and the net mass transports through the sections $L_{\alpha}$ were several orders in magnitude higher than "physically acceptable" values specified by prior statistics. An optimization procedure enabled us to reduce these imbalances to a level consistent with their prior uncertainties.

A large number of sensitivity experiments were conducted to investigate the influence of the magnitudes of $W_{\theta, S}^{t}$ and $\mathbf{W}_{\psi}^{s}$ on the final flow field obtained after nonlinear optimization. Diffusion coefficients present in the dynamical constraints were also varied with the order in magnitude. The experiments have shown that the optimal state is stable with respect to horizontal diffusion variation within the range of $10^{6}-10^{7} \mathrm{~cm}^{2} \mathrm{~s}^{-1}$. The vertical diffusion coefficient was varied within the ranges of $1-10 \mathrm{~cm}^{2} \mathrm{~s}^{-1}$ in the upper layer $(0-50 \mathrm{~m})$ and $0.1-1 \mathrm{~cm}^{2} \mathrm{~s}^{-1}$ below. The best fit to climatologies was obtained for the values of 8 and $0.3 \mathrm{~cm}^{2} \mathrm{~s}^{-1}$, respectively. The magnitude of $\mathbf{W}_{\psi}^{s}$ was optimized to obtain a compromise between the presence of unrealistic grid-scale features in the optimal transport pattern and its oversmoothing. The optimized patterns have shown low sensitivity to the prior error bars in atmospheric forcing, which were varied within the limits of $10-50 \mathrm{~W} \mathrm{~m}^{-2}, 10-50 \mathrm{~cm} \mathrm{yr}^{-1}$, and $0.1-0.5 \mathrm{dyn} \mathrm{cm}^{-2}$ for the fluxes for heat, freshwater, and momentum, respectively. The timescale $T^{*}$, which defines the magnitudes of $W_{\theta, S}^{t}$, was varied within the range of 5-100 years. Experiments have shown that larger values of $T^{*}$ do not affect the optimal values of the residuals but, instead, reduce the convergence rate of the optimization algorithm because of stronger nonlinearity. The latter increases because with an increase of $T^{*}$, the relative weight of the nonlinear advectivediffusive balance constraints is also increased and the shape of $\mathfrak{I}$ is displaced farther from purely quadratic.

Sensitivity studies were the most computationally expensive part of the analysis. Each assimilation experiment required several thousand iterations to reduce the gradient of the cost function by 5 orders in magnitude. The total number of trial assimilation runs exceeded 250 .

\subsection{Error Analysis}

Having defined the prior probability distribution and the optimal state, one can study mean variations of arbitrary linear functions $\mathscr{L}$ of the state variables (e.g., transports and heat and salt fluxes) that arise because of the uncertainties specified by the prior Gaussian statistics. These variations can be naturally treated as posterior errors.

The formal technique of that error analysis has been outlined a number of times [e.g., Thacker, 1989], but its practical applications in oceanographic literature are rather scanty 


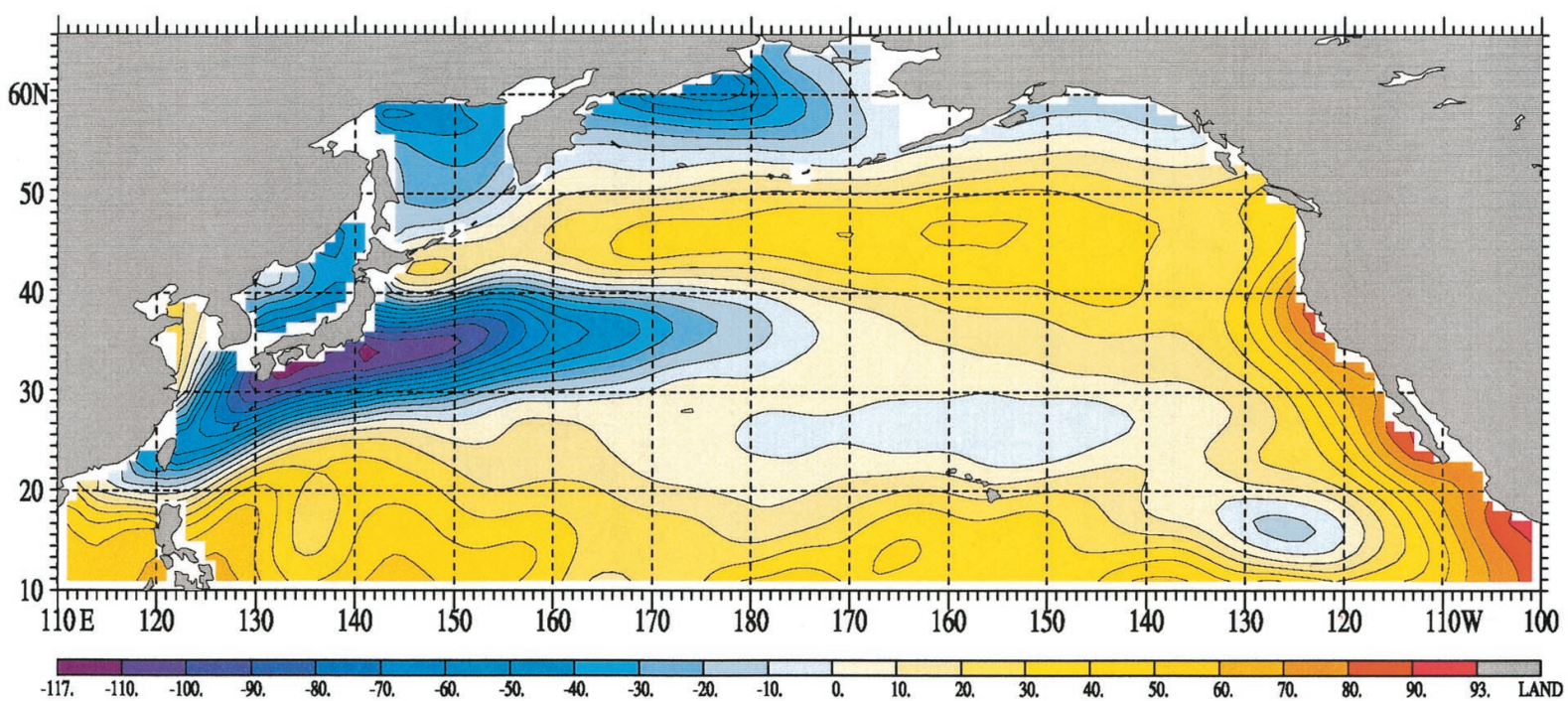

Plate 1. Optimized annual mean ocean-atmosphere heat flux. Negative values correspond to ocean cooling. The contour interval is $10 \mathrm{~W} \mathrm{~m}^{-2}$.

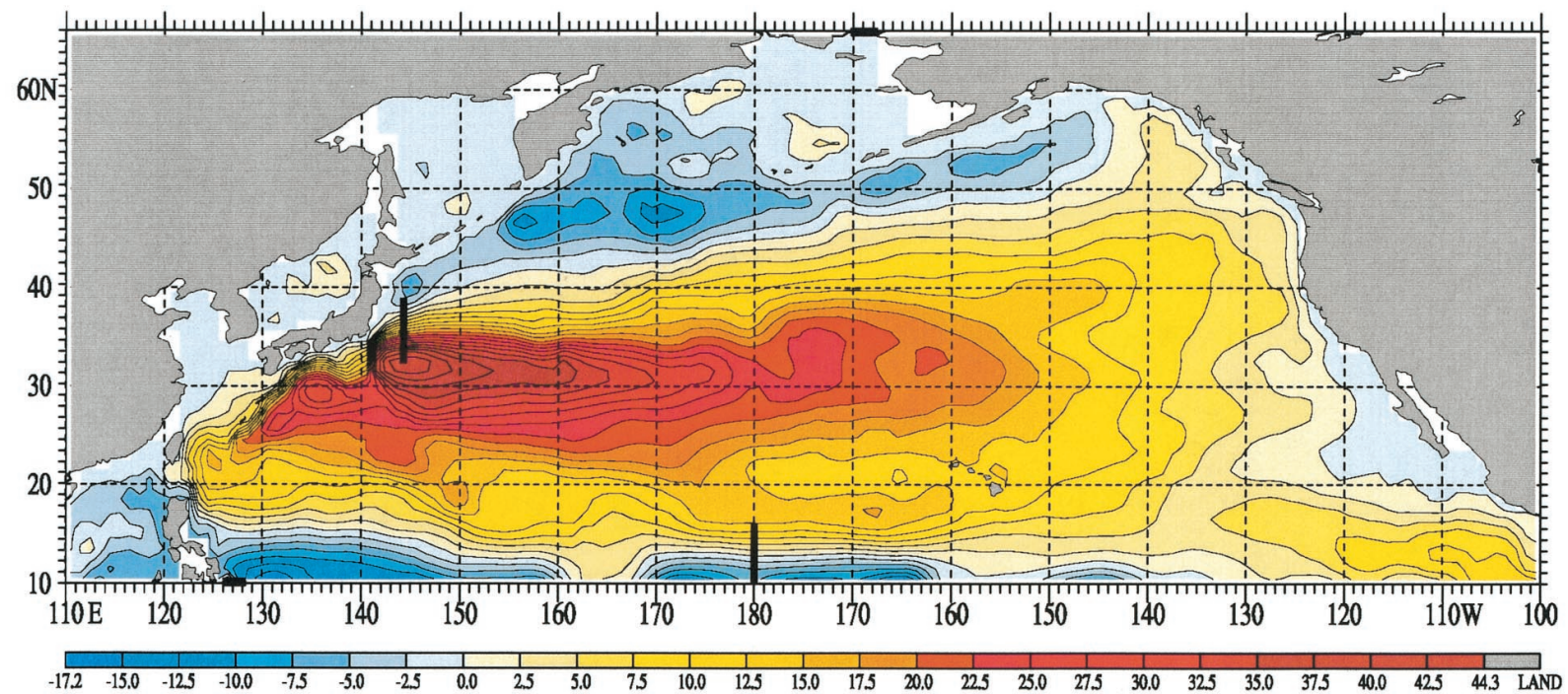

Plate 2. Total transport stream function of the optimal state. The contour interval is $2.5 \mathrm{~Sv}$. The thick lines denote four sections whose transport estimates were included in the cost function.

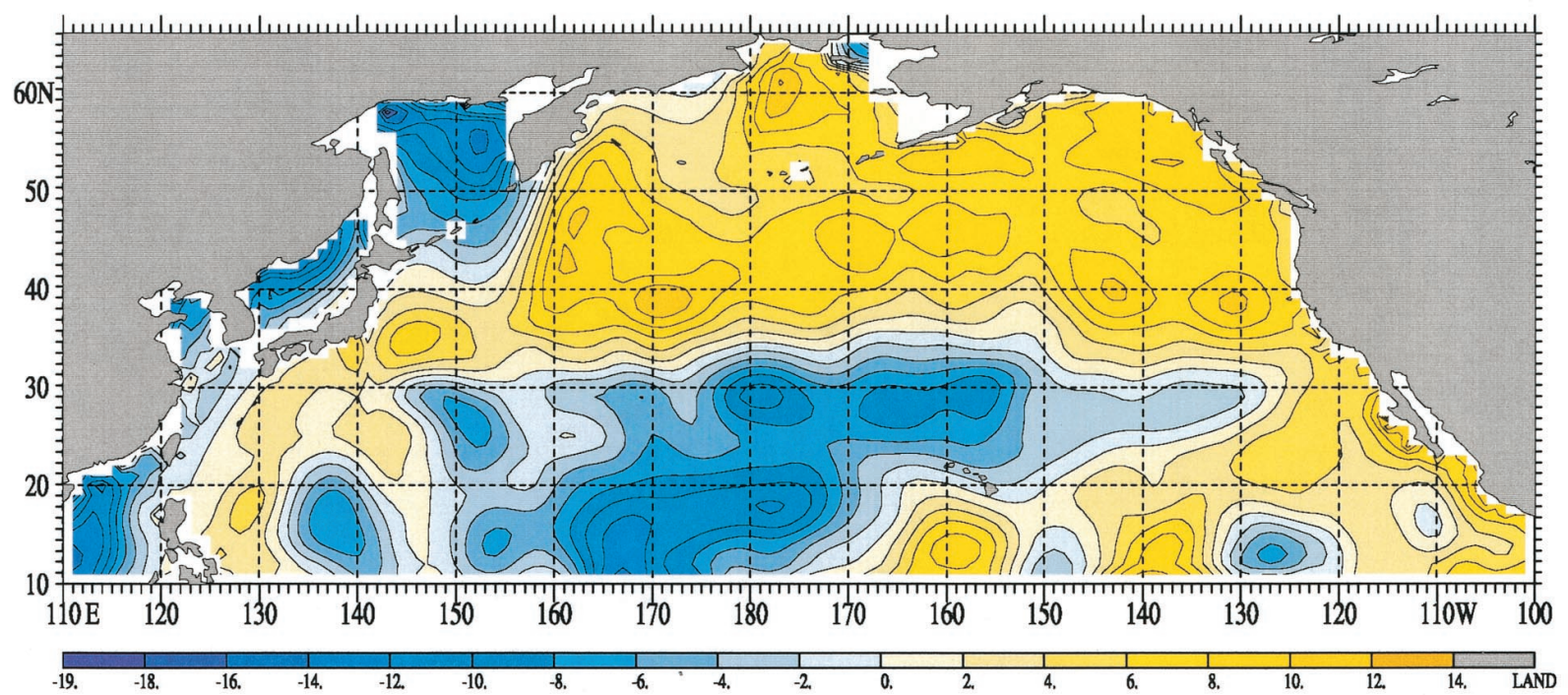

Plate 3. Difference between the optimized heat flux and climatological data. The contour interval is $2 \mathrm{~W} \mathrm{~m}^{-2}$. 


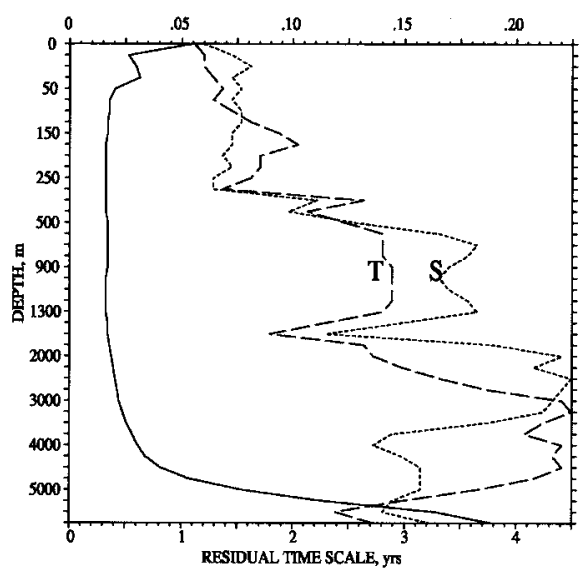

Figure 3. Vertical distributions of the mean relative error of the temperature/salinity fields (solid line) and the timescales of the residual variability of these fields for the optimized state.

[Gunson and Malanotte-Rizzoli, 1996; Yaremchuk et al., 1998]. The major obstacle is the high computational cost of error estimation, which requires an inversion of the Hessian matrix $\mathbf{H}$ associated with the assimilation scheme. Yaremchuk et al. [1998] utilized an implicit inversion algorithm to solve the system of linear equations $\mathbf{H X}=\mathscr{L}$ and then obtained the error estimate $\boldsymbol{\varepsilon}^{2}(\mathscr{L})=\mathscr{L}^{T} \mathbf{X}$. In the present study a modified approach has been applied. The underlying idea is to factorize the formula for error estimation:

$$
\varepsilon^{2}(\mathscr{L})=\mathscr{L}^{T} \mathbf{H}^{-1} \mathscr{L}=\mathscr{L}^{T} \frac{1}{\sqrt{\mathbf{H}}} \frac{1}{\sqrt{\mathbf{H}}} \mathscr{L} \equiv \mathscr{2}^{T} \mathscr{Q} .
$$

The auxiliary vector $\mathscr{2}=\sqrt{\mathbf{H}^{-1}} \mathscr{L}$ can be computed through an iterative procedure that is based upon the expansion of $\sqrt{\mathbf{H}^{-1}}$ in orthogonal polynomials of $\mathbf{H}$. Prior to the expansion the Hessian spectrum is normalized by its maximum eigenvalue. In the computations we used the Chebyshev polynomials $\mathcal{T}^{n}$ as basis functions:

$$
\mathscr{2}=\frac{4}{\pi} \sum_{n=1}^{\infty} \frac{n}{n^{2}-\frac{1}{4}} \mathscr{T}^{n-1}(\mathbf{H}) \mathscr{L},
$$

so that the polynomial of the $n$th order could be computed recursively [Bateman et al., 1953]:

$$
\mathscr{T}^{n}=2(\mathbf{E}-2 \mathbf{H}) \mathscr{T}^{n-1}-\mathscr{T}^{n-2}, \quad \mathscr{T}^{0}=\mathbf{E}, \quad \mathscr{T}^{1}=2(\mathbf{E}-2 \mathbf{H}) \mathscr{T}^{0} .
$$

In these expressions, $E$ stands for the identity operator.

An obvious disadvantage of the method is its inefficiency in cases when exact error estimates are necessary. Since basis functions are not $\sqrt{\mathbf{H}}$-orthogonal, one needs an infinite number of iterations to obtain absolute accuracy, while most of the iterative inversion methods guarantee absolute convergence in $D=\operatorname{dim} \mathscr{L}$ iterations. In practice, however, the cost function structure is rather subjective and uncertain and one needs only a rough error estimate, which should be obtained through a moderate number of iterations. In that case the proposed scheme may be advantageous for two reasons. First, because the symmetry of formulation, covariance matrix estimates obtained after any finite number of iterations are always symmetric and positive definite. Second, the system of equations $\sqrt{\mathbf{H}} \mathscr{2}=\mathscr{L}$ is much better conditioned than the one solved within the framework of the standard scheme.
In actual computations, 55 transport operators, $\mathscr{L}_{\gamma}, \gamma=$ $1, \ldots, 55$, were subjected to the error analysis. All the operators were linearized in the vicinity of the optimal state to comply with the assumption that posterior statistics are also Gaussian.

\section{Steady State Circulation}

\subsection{Consistency With Observations}

After a careful choice of prior statistics and model parameters the final assimilation was performed. One may treat the obtained optimal state as an ensemble mean circulation under the forcing conditions typical of the beginning of the $1990 \mathrm{~s}$ because a large portion of underlying data was collected during that period. Although the large-scale circulation strongly depends on nonlinear processes, one hopes that the mean fields still contain interesting information. Also of interest is whether modern climatologies are consistent with each other in the framework of the large-scale steady state circulation dynamics.

Figure 3 demonstrates vertical distributions of the mean model-data misfit with WOCE hydrology relative to horizontal mean variations $\sigma(\theta)$ and $\sigma(S)$ of temperature and salinity and the residual variability timescale in temperature and salinity fields. The first curve fits well within error bars of the hydrological data. In the upper layers, rms errors in temperature and salinity do not exceed $10 \%$ of $\sigma(\theta)$ or $\sigma(S)$ over the NP (or $0.63^{\circ} \mathrm{C}$ and $0.083 \mathrm{psu}$, respectively). In the deep layers the relative error grows considerably but remains within acceptable limits (e.g., $0.009^{\circ} \mathrm{C}$ and 0.001 psu at $5250 \mathrm{~m}$ ). Residual variability timescales, defined as the ratios $\sigma(\theta) / \sigma\left(F_{\theta}^{e}\right)$ and $\sigma(S) / \sigma\left(F_{S}^{e}\right)$, appear to be somewhat smaller than their prior value of 10 years. A closer look shows, however, that this is generally due to the scheme's inability to reduce $F^{e}$ in the subdomains occupied by the Kuroshio, its extension, and some other dynamically active regions of the ocean. In these areas, typical residual timescales retain high values within the range of 100-150 days, while in the bulk of the ocean, typical values are 8-15 years. We assume that this is just a dynamical consequence of much higher mesoscale activity, which cannot be adequately parameterized by our simple turbulent closure. Nevertheless, the optimized stream function field has a number of common features with the result of Semtner and Chervin [1992], who integrated a $1 / 4^{\circ}$ primitive equation model for 32.5 years to obtain the mean circulation. The pattern in Plate 2 contains qualitatively the same eddy-like features in the Kuroshio/Oyashio region and the double gyre structure of the subpolar region as they are given by Semtner and Chervin [1992, Figure 10].

The SSH and atmospheric forcing fields of the optimal state also lie within their prior error bars with rms misfits of $18 \mathrm{~cm}$,

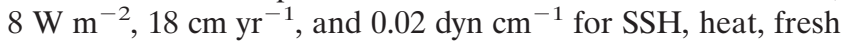
water, and momentum fluxes, respectively. The difference between the optimized heat flux and climatology is shown in Plate 3. The most significant departure from the data is observed in the northern part of the Okhotsk Sea where the climatological heat flux into the ocean seems to be overestimated by $10-15 \mathrm{~W}$ $\mathrm{m}^{-2}$. On the basin scale the mean heat flux is biased by $0.9 \mathrm{~W}$ $\mathrm{m}^{-2}$ in the direction of warming, increasing the net climatological NP heating rate by $0.05 \mathrm{PW}$. However, regarding the error bars for atmospheric forcing, these changes cannot be considered statistically significant.

The rms discrepancy between the optimal state and TOPEX/ Poseidon altimetry is considerably lower south of $45^{\circ} \mathrm{N}$ (Plate 

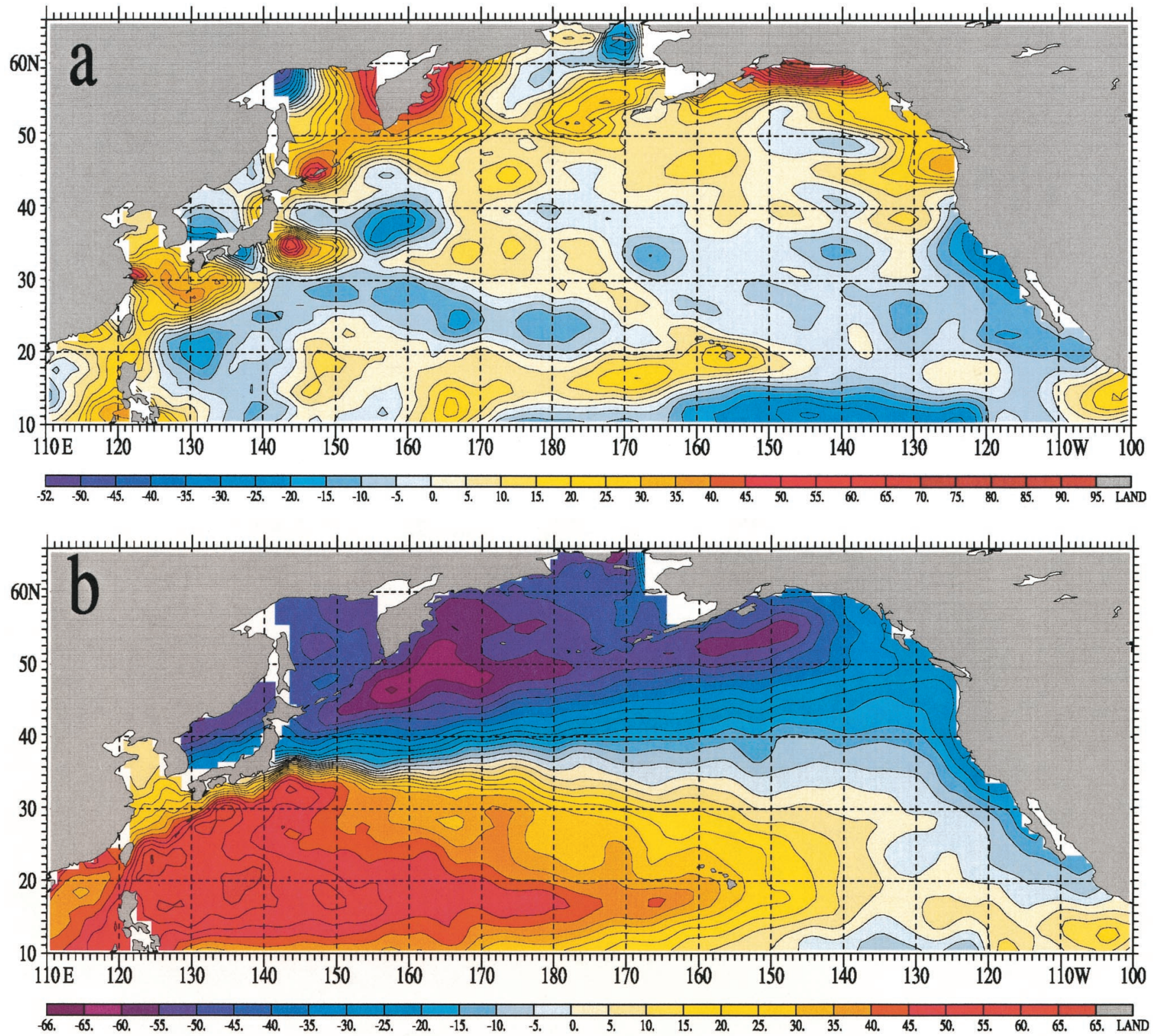

Plate 4. (b) Optimized sea surface elevation and (a) its discrepancy with the TOPEX/Poseidon data. The contour interval is $10 \mathrm{~cm}$.

4). The error field shown in Plate 4 has a dominant spatial scale of a few hundred kilometers, which corresponds to higher uncertainties of smaller-scale harmonics in the JGM-3 geoid model. The optimized SSH pattern shown in Plate $4 \mathrm{~b}$ bears most of the features present in the output of high-resolution GCMs. Nevertheless, it fails to reproduce distinctly the Subarctic Front signal around $41^{\circ} \mathrm{N}, 150^{\circ}-160^{\circ} \mathrm{E}$, possibly because of unadequate horizontal resolution.

Drifter velocity misfit $\left(9 \mathrm{~cm} \mathrm{~s}^{-1} \mathrm{rms}\right)$ appears to be relatively large, but it is still consistent with the data error level. As is seen from Figure 2 and the velocity error relationship, the dominant part of the ocean is occupied by grid cells with rms velocity errors of $10-15 \mathrm{~cm} \mathrm{~s}^{-1}$.

The rms variation of the bottom boundary condition error decreased $\sim 3$ orders in magnitude after optimization, attaining the value $1.2 \mathrm{~m} \mathrm{yr}^{-1}$. The optimized net transport into the $\mathrm{BBL}$ is equal to $0.01 \mathrm{~Sv}$ or, equivalently, $0.5 \mathrm{~m} \mathrm{yr}^{-1}$. Consequently, the net mass balance of the optimal NP state can be treated as exact since the errors associated with BBL pumping are much smaller than other mass balance uncertainties, introduced by errors in the freshwater balance at the ocean surface and by river runoff.

Finally, optimized transports through the four selected sections also lie within their prior error bars. As a consequence, one can state that the model is consistent with the data in the framework of the statistical hypothesis outlined in section 3.1.

\subsection{Velocity Field and Transports}

Table 1 presents an inventory of the transports and the heat and salt fluxes of the major circulation features of the optimized state. All the transports were computed by integrating the fluxes to the bottom across the sections whose locations are given in the last column of Table 1 . Heat and salt fluxes are given relative to $0^{\circ} \mathrm{C}$ and $0 \mathrm{psu}$, respectively. Most of the transport values are well determined in the sense of posterior variances, but their "ensemble mean" values appear to be somewhat lower than those observed in oceanographic literature. For instance, according to Cokelet and Schall [1996], the 
Salinity

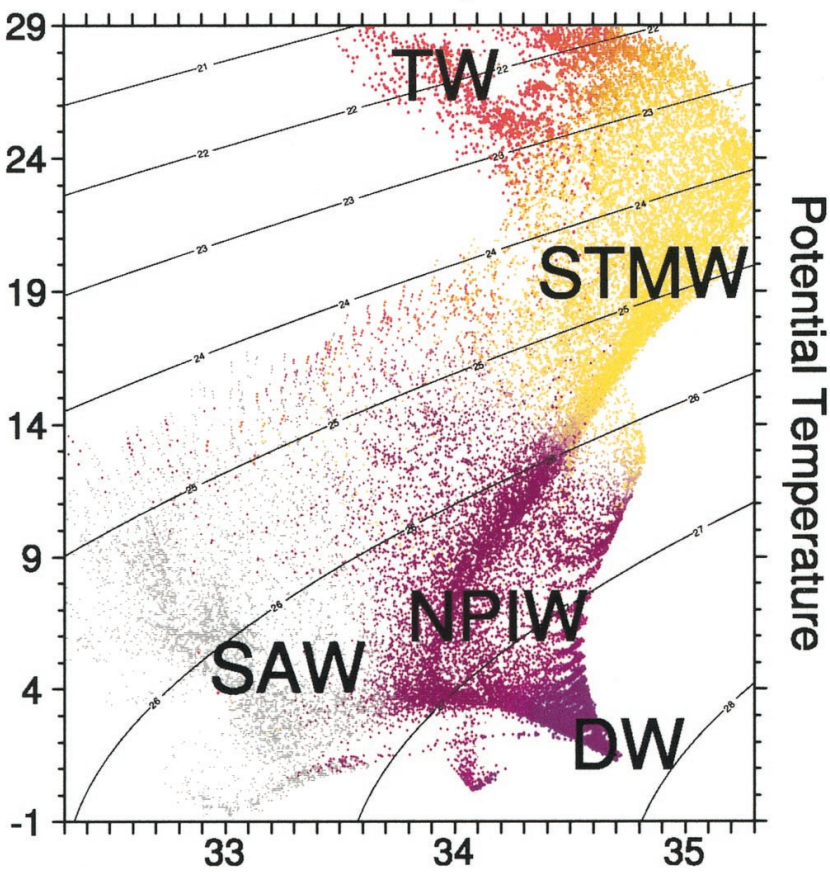

Plate 5. Water masses of the optimal state.

acoustic Doppler current profiler (ADCP)-referenced Alaskan current's transport at $179^{\circ} \mathrm{E}$ is $28 \mathrm{~Sv}$, while the Kamchatka current's transport at $55^{\circ} \mathrm{N}$ is $14 \mathrm{~Sv}$. Purely geostrophic estimates referenced to 1500 dbar usually give $30 \%$ lower transports for these currents, which are more consistent with the results of Semtner and Chervin [1992]. The optimized value of the Oyashio transport computed between 0 and $1000 \mathrm{dbar}$ at $46^{\circ} \mathrm{N}$ reaches $21 \mathrm{~Sv}$, corresponding well with the numerous estimates taken from direct observations. The much smaller value of the total transport (line 4 in Table 1 ) is due to a persistent deep countercurrent flowing northeast along the Kuril-Kamchatka trench (Figure 4b).

Circulation at middepth is shown in Figure 4a. Among other features of particular interest are two gyres visible south of $25^{\circ} \mathrm{N}$ at $153^{\circ} \mathrm{E}$. They were recently diagnosed by Wiffels et al. [1998], who processed the WOCE hydrographic section along $149^{\circ} \mathrm{E}$.

Figure 5 demonstrates the NP overturning circulation north of $20^{\circ} \mathrm{N}$. The patterns have been obtained by zonal integration of the velocity field. Patterns of this kind demonstrate large variability in oceanographic literature. Nevertheless, two qualitative features are assumed to be well established: a shallow clockwise cell (CC1) in the south and a counterclockwise cell (CCC) generated by the net upwelling in the midlatitudes. CC1 and CCC transports usually vary by $12-18$ and 3-9 Sv, respectively. Existence of the clockwise cell north of $50^{\circ}$ (CC2) is rather questionable. Table 2 gives an inventory of these transports found in the latest literature.

One difference in the optimized estimate obtained in the present study is the presence of a relatively strong CC2 with a transport of $3.2 \pm 1.4 \mathrm{~Sv}$. Kinematically, this feature arises because of deep downwelling along the northwestern coast of Russia between $165^{\circ} \mathrm{E}$ and the dateline. Considerable contributions to that cell are provided by the coastal region of North America between $140^{\circ}$ and $152^{\circ} \mathrm{W}(0.4 \pm 1.0 \mathrm{~Sv})$ and the northern coast of the Sea of Okhotsk $(0.6 \pm 1.2 \mathrm{~Sv})$. The magnitude of $\mathrm{CC} 2$ was dependent on the inverse variances $W_{\theta, S}^{e}$ penalizing the basin-scale integrals of the residuals in the tracer balance equations. The optimized value of the $\mathrm{CC} 2$ transport was $5.3 \pm 1.4 \mathrm{~Sv}$ when $W_{\theta, S}^{e}$ were set to zero. Nevertheless, the structure was persistent throughout all the sensitivity experiments and thus cannot be attributed to the statistical hypothesis of the interpolation algorithm. Both climatological and the optimal heat flux distributions demonstrate considerable cooling of the ocean surface in those regions (Plate 1), with the annual average values of 50-70 W $\mathrm{m}^{-2}$. One can speculate that excessive cooling at the western coast of the Bering Sea may weaken stratification in that region

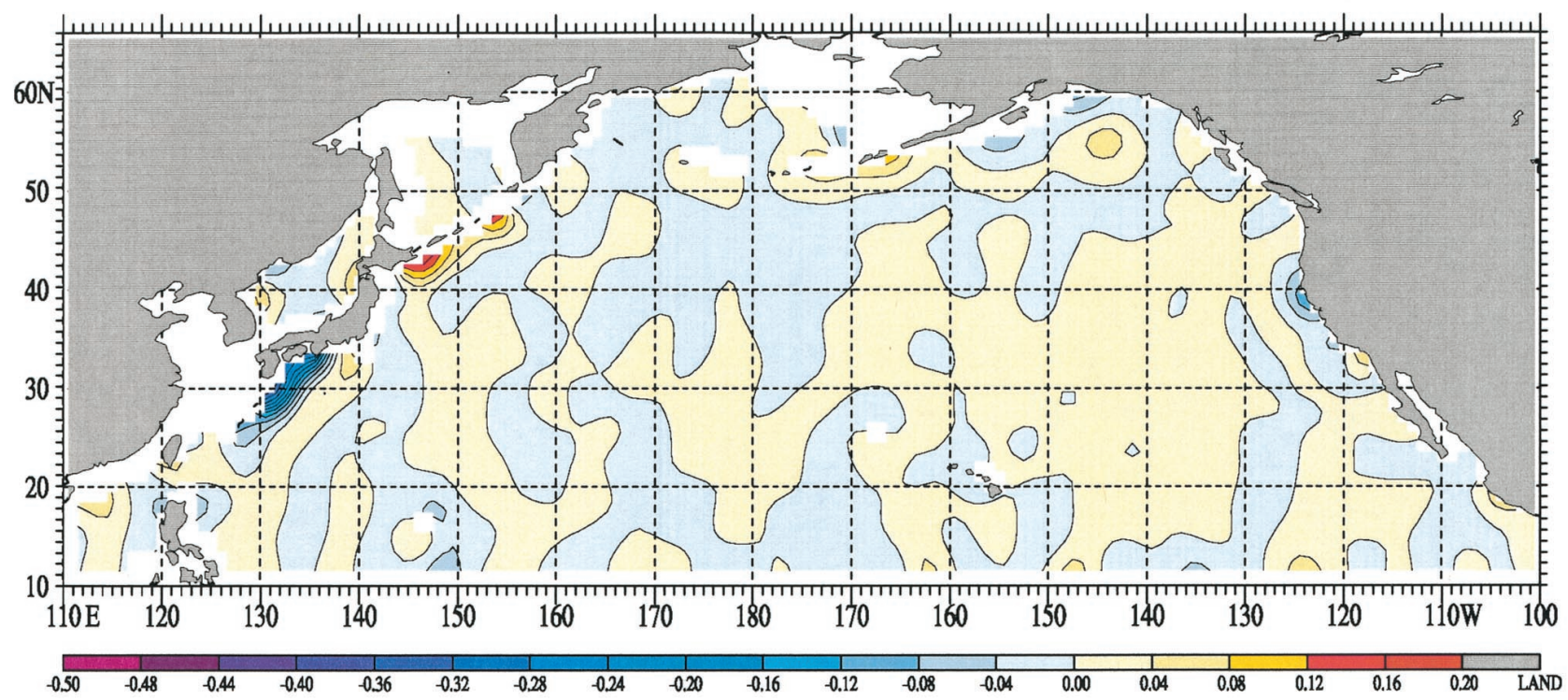

Plate 6. Horizontal divergence of the total transport between isopycnals $\sigma_{\theta}=26.7$ and $\sigma_{\theta}=27.0$. The contour interval is $0.04 \mathrm{~Sv}$. 


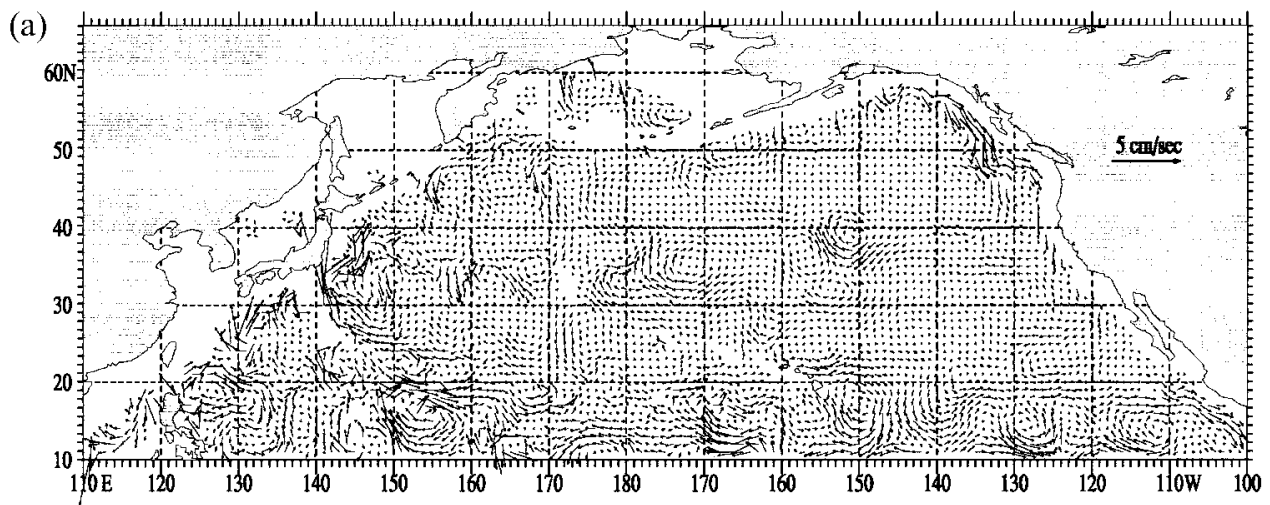

(b)

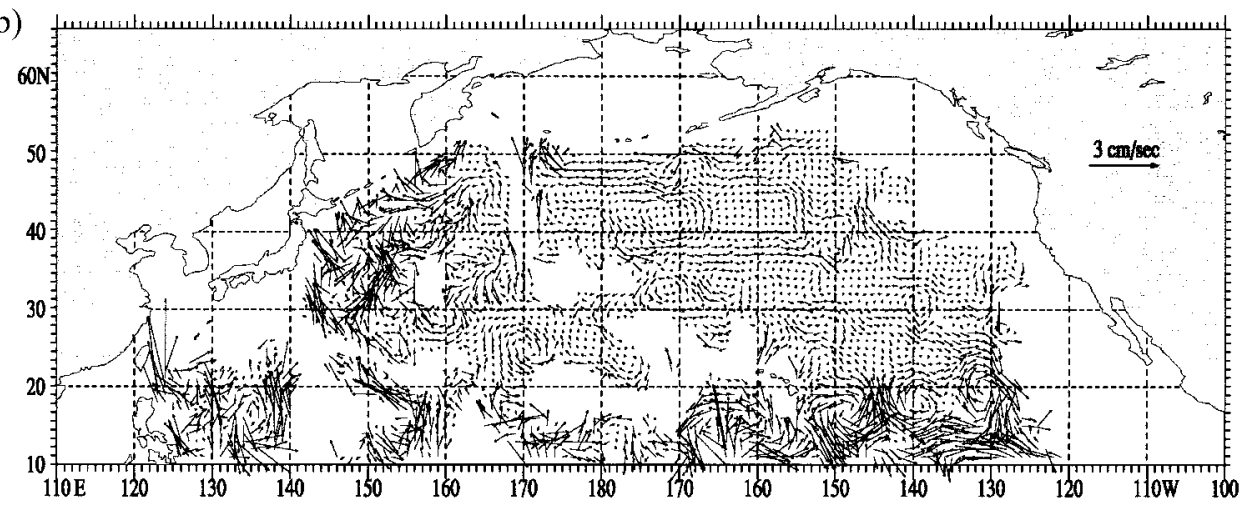

Figure 4. Optimized horizontal currents at (a) 1750 and (b) $4250 \mathrm{~m}$.

and trigger a considerable downwelling supplied by water entering the basin through the Aleutian passages [Toggweiler and Samuels, 1998]. Another possible mechanism contributing to CC2 transport may be associated with boundary layer plumes, formed at the shelves of the northwestern Bering and Okhotsk Seas [Harvey, 1996].

The relatively large amount of deep water entering the NP from the south is another interesting feature of the overturning circulation. In the global models of Semtner and Chervin

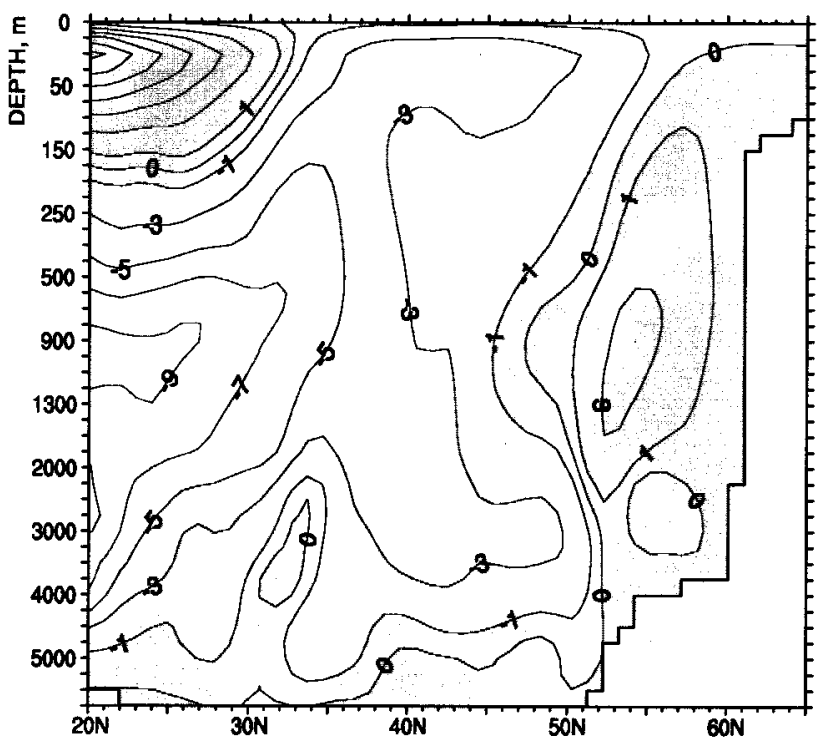

Figure 5. Meridional overturning stream function (Sv) for the optimal state.
[1992], Fujio et al. [1992], and Hirst et al. [1996] the net inflow from the south at $20^{\circ} \mathrm{N}$ does not exceed 2-3 Sv, showing no distinct confinement to deep layers. Ishizaki [1994], who focused on simulation of the NP abyssal circulation, obtained a net inflow of $4 \mathrm{~Sv}$ below $3800 \mathrm{~m}$. The optimized pattern in Figure 5 shows a CCC transport of $8.4 \pm 2.4 \mathrm{~Sv}$ with $7.1 \mathrm{~Sv}$ inflowing below $3750 \mathrm{~m}$. The major contribution to this flow comes from Kuroshio southeast of Taiwan (4 Sv) and arrives by the relatively well established pathway of deep waters from the South Pacific that is located between $150^{\circ}$ and $160^{\circ} \mathrm{E}$ (Figure 4b) [Ishizaki, 1994; Kawabe and Taira, 1995]. Schmitz [1995], in his qualitative overview of the experimental results on the global thermohaline circulation, indicates a $10 \mathrm{~Sv}$ inflow of deep water across $10^{\circ} \mathrm{N}$ in the Pacific. According to Schmitz the southward return flow is associated with the NP Deep Water, a water mass that is defined by silicate maximum and located in the depth range of 2-3 km. In his recent work, Reid [1997] also shows a net inflow of $\sim 10 \mathrm{~Sv}$ at $20^{\circ} \mathrm{N}$ in the layers below $4000 \mathrm{~m}$. Pathways of that inflow qualitatively coincide with the pattern in Figure 4b. Thus our result might be considered a quantification of Reid's scheme. It is necessary to note that the magnitude of CCC transport depended on the values of $W_{\theta, S}^{e}$. At $W_{\theta, S}^{e}=0$ the CCC transport was close to $11.6 \pm 2.4 \mathrm{~Sv}$ with $7.2 \mathrm{~Sv}$ arriving below $4000 \mathrm{~m}$. In contrast, at very large values of $W_{\theta, S}^{e}, \mathrm{CCC}$ transport never decreased below $5 \mathrm{~Sv}$, but in such cases the degree of "steadiness" of the optimal state started to decrease as a result of the increasing influence of the $W^{e}$ term on the cost function balance.

The well-established subtropical overturning cell CC1 did not show any dependence on $W_{\theta, S}^{e}$ : its transport varied within 12.8-14.4 Sv through the whole set of sensitivity experiments. 
Table 1. Mass, Salt, and Heat Transports

\begin{tabular}{lcrrr}
\hline \multicolumn{1}{c}{ Circulation Feature } & $\begin{array}{c}\text { Mass, } \\
\mathrm{Sv}\end{array}$ & $\begin{array}{c}\text { Salt, } \\
\text { kton s }^{-1}\end{array}$ & \multicolumn{1}{c}{$\begin{array}{c}\text { Heat, } \\
10^{13} \mathrm{~W}\end{array}$} & $\begin{array}{c}\text { Section } \\
\text { Location }\end{array}$ \\
\hline Kuroshio & $50 \pm 08$ & $101 \pm 17$ & $166 \pm 31$ & $33^{\circ}-38^{\circ} \mathrm{N}, 144^{\circ} \mathrm{E}$ \\
Kuroshio extension & $31 \pm 06$ & $54 \pm 11$ & $128 \pm 38$ & $33^{\circ}-38^{\circ} \mathrm{N}, 160^{\circ} \mathrm{E}$ \\
Subarctic Current & $16 \pm 14$ & $05 \pm 09$ & $01 \pm 23$ & $40^{\circ}-46^{\circ} \mathrm{N}, 170^{\circ} \mathrm{E}$ \\
Oyashio & $09 \pm 04$ & $-24 \pm 13$ & $-09 \pm 12$ & $47^{\circ} \mathrm{N}, 153^{\circ}-157^{\circ} \mathrm{E}$ \\
Alaska Current & $06 \pm 12$ & $-15 \pm 08$ & $-05 \pm 12$ & $53^{\circ}-55^{\circ} \mathrm{N}, 157^{\circ} \mathrm{W}$ \\
Bering Strait & $01 \pm 00$ & $03 \pm 02$ & $03 \pm 02$ & $66^{\circ} \mathrm{N}$ \\
California Current & $08 \pm 13$ & $-10 \pm 21$ & $-21 \pm 21$ & $38^{\circ} \mathrm{N}, 123^{\circ}-128^{\circ} \mathrm{W}$ \\
Mindanao current & $12 \pm 07$ & $-39 \pm 13$ & $-31 \pm 14$ & $10^{\circ} \mathrm{N}, 126^{\circ}-129^{\circ} \mathrm{E}$ \\
North Equatorial Current & $14 \pm 12$ & $-05 \pm 21$ & $-33 \pm 30$ & $10^{\circ}-22^{\circ} \mathrm{N}, 145^{\circ} \mathrm{W}$ \\
North Equatorial Current & $28 \pm 11$ & $-80 \pm 26$ & $-215 \pm 35$ & $10^{\circ}-22^{\circ} \mathrm{N}, 135^{\circ} \mathrm{E}$ \\
\hline
\end{tabular}

\subsection{Heat and Salt Budget}

Heat and salt fluxes and their divergences are the values quantifying the global thermohaline circulation and oceanatmosphere coupling. Meridional NP heat fluxes across the benchmark sections at $24^{\circ}$ and $35^{\circ} \mathrm{N}$ have been estimated by many. Most of the analyses utilize data from hydrographic sections, and the results vary widely, between -1.0 [Bryan, 1962] and 0.76 \pm 0.3 PW [Bryden, 1991]. Both positive (northward) and negative (southward) heat fluxes in this latitude band were diagnosed by Roemmich and McCallister [1989], who estimated that the net NP heat loss between $24^{\circ}$ and $35^{\circ} \mathrm{N}$ is close to $0.9 \mathrm{PW}$. Formal errors of all these estimates usually vary within $0.3-0.7 \mathrm{PW}$.

Heat and salt transports for specific circulation features shown in Table 1 are in good agreement with a number of estimates presented by various authors: for example, the $\mathrm{Ku}$ roshio heat transport corresponds well to the result of McBean [1991], who obtained the value of 1.76 PW. These estimates, however, are quite sensitive to the magnitudes of total transport through the corresponding sections and to the reference values of temperature and salinity. Therefore of special interest are the horizontal divergences of the heat and salt fluxes. In the foregoing presentation the contribution of $F_{\theta, S}^{e}$ is included in the net diffusive fluxes. This is done for simplicity of presentation and does not affect the analysis because the imbalance caused by residuals is negligible compared to advective fluxes and atmospheric forcing and lies far within the error bars of their integral estimates.

The integral advective (adv), diffusive (dif) and atmospheric forcing (atm) fluxes as functions of the cutoff latitude are shown in Figure 6. Climatological atmospheric fluxes of heat and fresh water (ref) are given for comparison. Since the net fluxes through the Bering Strait are relatively small, the plots can be viewed as latitudinal variations of the net meridional fluxes in the North Pacific. Numerically, the curves are in slight imbalance (invisible by eye) owing to finite advection into the

Table 2. Overturning Circulation in the North Pacific

\begin{tabular}{lccc}
\hline \multicolumn{1}{c}{ Source } & CC1, Sv & CCC, Sv & CC2, Sv \\
\hline Semtner and Chervin [1992] & 16 & 5 & $<1$ \\
Fujio et al. [1992] & 12 & 9 & 4 \\
Ishizaki [1994] & 18 & 5 & $<1$ \\
Hirst et al. [1996] & 10 & 3 & - \\
present study & $13 \pm 3$ & $8 \pm 2$ & $3.2 \pm 1.4$ \\
& & & \\
\hline
\end{tabular}

BBL. The magnitude of that advection, however, is negligible compared to error level of the fluxes.

As is seen in Figure 6, the major balance occurs between the advective fluxes of heat, fresh water, and atmospheric forcing, while diffusive fluxes of $\theta$ and $S$ play a minor role. Heat is advected southward at all latitudes south of $50^{\circ} \mathrm{N}$. The advection rate, however, starts to be statistically significant only south of $15^{\circ} \mathrm{N}$, where the net NP heating rate exceeds $0.3 \mathrm{PW}$. At all other latitudes the advection rate varies within $0.05-0.15$ PW. The freshwater flux changes its sign at $20^{\circ} \mathrm{N}$. North of that latitude, fresh water is transported southward at the rate of 0.1-0.2 Sv, corresponding to the predominance of precipitation over evaporation. The net southward advective heat flux at midlatitudes is caused by two conditions imposed by the data. First, atmospheric climatology does not show any significant ocean cooling over the NP: the net ocean-atmosphere heat flux varies within $\pm 0.1 \mathrm{PW}$ north of $20^{\circ} \mathrm{N}$ (Figure 6a). Second, hydrology in combination with drifters and altimetry indicates an inflow of cold deep water (Figure 5) from the south with the compensating southward return flow in the upper layers, which is warmer than the deep water. This circulation pattern persists at midlatitudes. A certain amount of heat is transported northward by the shallow subtropical cell $\mathrm{CC} 1$ seen in the upper left corner of Figure 5, but its contribution to the net heat budget between $10^{\circ}$ and $30^{\circ} \mathrm{N}$ seems to be minor. The major cause of the southward heat advection is the absence of significant net heat loss to the atmosphere at midlatitudes; such advection was present, for instance, in the computations of Semtner and Chervin [1992]. It is noteworthy that the net fresh water transport obtained by Semtner and Chervin is much more consistent with our result (Figure 6b) owing to closer correspondence of the atmospheric freshwater fluxes.

It should be noted that model-data misfit in atmospheric forcing never exceeded $20 \%$ of its horizontal rms amplitude in our assimilation runs and that the net southward heat advection was a persistent feature of the interpolation pattern through all the sensitivity experiments. The magnitude of that advection was, however, dependent on $W_{\theta, S}^{e}$. Without any constraints on the integrals of the residuals, southward heat advection varied within $0.2-0.4 \mathrm{PW}$ in the latitude band $20^{\circ}$ $40^{\circ} \mathrm{N}$. The advection was, however, compensated by the integrals of the residual fields, leaving the atmospheric heat flux virtually unchanged.

The error bars for the optimized heat and salt transport estimates remain quite large (Figure 6 and Table 1), indicating that hydrological data fail to constrain significantly the poorly known atmospheric forcing within the framework of the uti- 

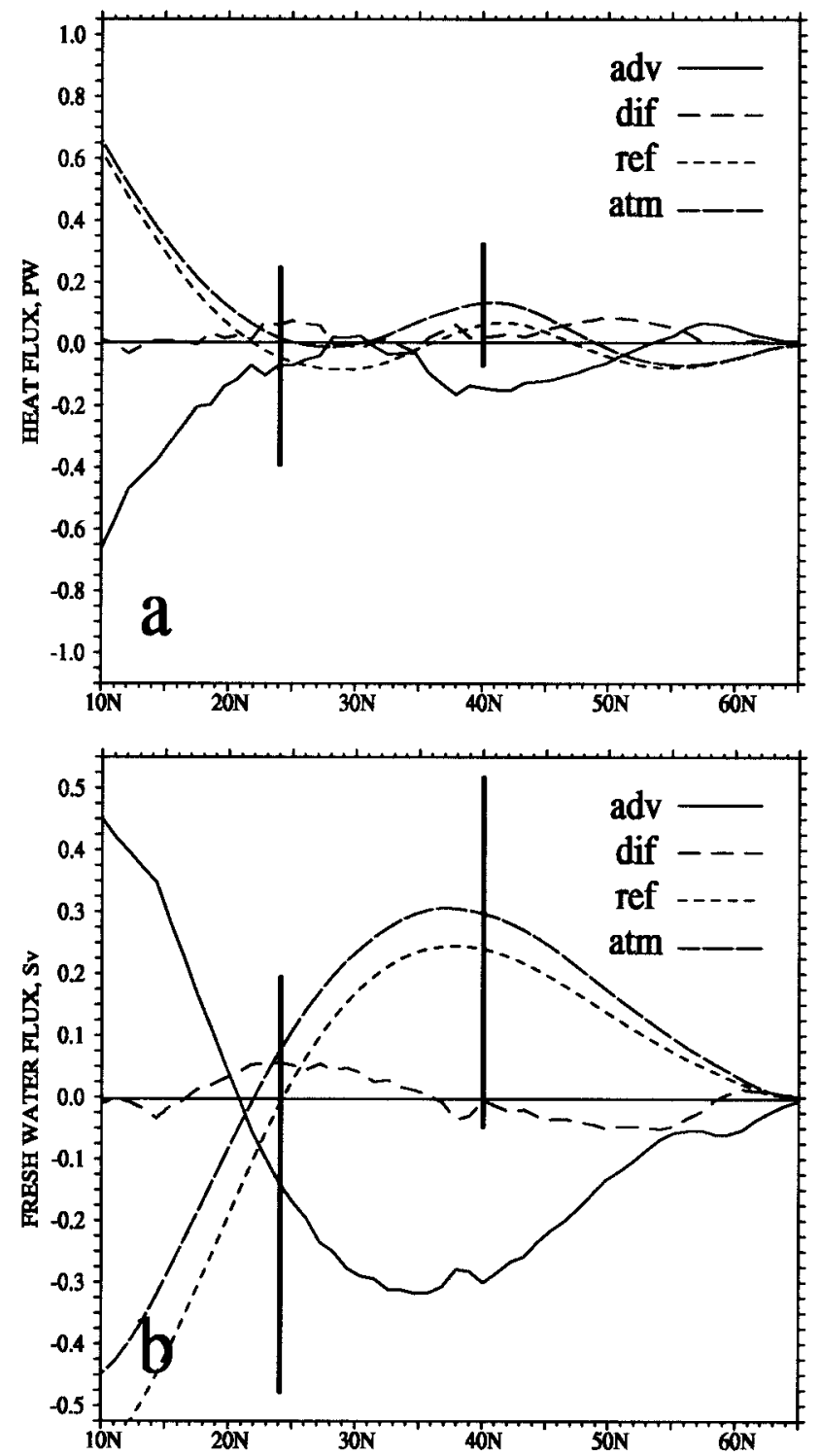

Figure 6. Latitudinal dependence of the (a) net heat and (b) freshwater fluxes into the North Pacific. Error bars for the advective transports at $24^{\circ} \mathrm{N}$ and atmospheric fluxes at $40^{\circ} \mathrm{N}$ are shown.

lized closure scheme (ocean-atmosphere property fluxes are proportional to the corresponding large-scale gradients). This failure is due to relatively large prior errors in the surface temperature and salinity fields, which, in turn, cause large uncertainties in the vertical gradients. These uncertainties are found to be even larger than the errors in atmospheric forcing.

\subsection{Water Mass Transformations}

The objective analysis scheme and fine vertical resolution of the WOCE climatology were chosen to preserve the original water masses and eliminate spurious waters, usually originating as a result of horizontal smoothing of the $\theta$ and $S$ features. The dynamical interpolation scheme, on the other hand, provides all the necessary fields for estimating water mass transformations (WMT). A standard way to diagnose WMT within a limited volume $\Omega$ is to compute the advective volume exchange between the water masses, assuming them to be in a steady balance. Such a technique is widely used in observational oceanography. The method provides an estimate of the net effect of the thermohaline forcing and mixing on water mass transformations within $\Omega$.

Following the definitions of Kawabe and Taira [1998], the computational domain is divided into five distinctive subdomains occupied by the NP Subarctic Water (SAW), NP Intermediate Water (IW), Subtropical Mode Water (STMW), Tropical Mode Water (TMW), and NP Deep Water (DW). Plate 5 gives an insight into the position of these water masses in $\theta-S$ space. In the physical space, SAW, STMW, and TMW occupy the upper layers of the ocean north of $45^{\circ} \mathrm{N}$, at $15^{\circ}-$ $45^{\circ} \mathrm{N}$, and south of $15^{\circ} \mathrm{N}$, respectively. IW is characterized by the salinity minimum at intermediate layers and occupies the layer between isopycnal surfaces, $26.7<\sigma_{\theta}<27.0$. DW generally resides in the layers below $1000 \mathrm{~m}$. In reality, observational oceanographers distinguish more than 30 North Pacific water masses, which are separated from each other by numerous transition zones. Accurate analysis of the WMTs is beyond the scope of the present study. We roughly assume that any grid cell (any dot in Plate 5) of the computational domain is occupied by one distinct water mass.

Performing integration of the volume transports over water mass boundaries in physical space and assuming the steady state balance, one can obtain WMTs for every pair of the adjacent water masses. Such computations show that diffusive and mixing processes north of $20^{\circ}$ transform the inflowing $9 \mathrm{~Sv}$ of DW and $2 \mathrm{~Sv}$ of TMW into $5 \mathrm{~Sv}$ of IW and $5 \mathrm{~Sv}$ of STMW leaving the domain at the south and $1 \mathrm{~Sv}$ of SAW outflowing through the Bering Strait. North of $40^{\circ} \mathrm{N}, 2 \mathrm{~Sv}$ of DW and $6 \mathrm{~Sv}$ of STMW are transformed into $1 \mathrm{~Sv}$ of SAW and $7 \mathrm{~Sv}$ of IW. Therefore one may deduce that $2 \mathrm{~Sv}$ of IW are transformed back into STMW between $20^{\circ}$ and $40^{\circ} \mathrm{N}$. By varying the boundaries of integration domain, it is possible to derive more conclusions of that kind. This analysis, however, is very rough mainly because of the approximative nature of water mass classification shown in Plate 5a. To be more precise, it may be useful to treat the composition of the grid cells as a mixture of water masses taken in certain proportion and to increase the number of water masses, but such a detailed analysis lies beyond the scope of the paper.

Plate 6 demonstrates a map of the biharmonically smoothed divergence of the total transport computed between the isopycnal surfaces $26.7<\sigma_{\theta}<27.0$. These surfaces approximately limit the boundaries of NPIW, and the pattern gives an insight into the regions of IW formation in the North Pacific. The largest positive divergence values are located east of Hokkaido and South Kuril islands, where the Okhotsk Sea mode water meets the waters of Oyashio. Integration over that area provides an estimate of the IW production rate of $2.5 \mathrm{~Sv}$. This value corresponds with the results of Yasuda [1997], who placed the NPIW source water into that region and estimated its production rate as 3-7 Sv. Another (statistically insignificant) area of the IW formation $(0.5 \mathrm{~Sv})$ can be spotted in the Alaskan Gyre. Some observational evidence for IW production in that region has been obtained by Van Scoy et al. [1991]. Plate 6 also demonstrates that IW flow is consistent with isopycnal dynamics except for the formation regions and the region south of Honshu, where old NPIW is intensively eroded by mixing processes caused by Kuroshio meandering. 


\section{Discussion and Conclusions}

We have obtained a dynamically and statistically consistent circulation in the North Pacific Ocean by combining the WOCE climatology, Da Silva atmospheric fluxes, TOPEX/ Poseidon altimetry, and MEDS drifter velocities in the framework of a steady state numerical model. From the technical point of view the analysis bears a number of features that distinguish it from the recently made inversions of climatologies in the North Atlantic [Yu and Malanotte-Rizzoli, 1998] and Indian [Lee and Marotzke, 1997, 1998] Oceans.

The low computational cost of the model allows for carrying out a large number of sensitivity experiments prior to the final assimilation run. A relatively complete posterior error analysis that uses an iterative scheme for the approximation of the inverse square root of the Hessian matrix is conducted.

A new hydrological data set with a number of advantages over the well-known Levitus climatologies has been tested. The data allow double vertical resolution in the deep layers. The cost function features harmonic regularization and incorporates a number of prior transport estimates taken as an average of the results from the latest oceanographic literature.

In order to eliminate the influence of the residuals on the estimates of the basin-scale circulation features an additional term has been introduced into the cost function. It was assumed that the residual fields do not a priori contain any information on the processes undescribed by the model (like the ageostrophic component of the velocity field, the long-term temperature/salinity trends, and the eddy fluxes), and therefore their basin-scale integrals only contaminate the useful signal. Assuming that $F_{\theta, S}^{e}$ are entirely due to data and model errors, we managed to reduce their impact on the integral circulation features by correcting their prior statistics. An alternative way to tackle the problem is to treat the momentum balance in the weak form by introducing the residuals in the equations for velocity. With this approach one can easily set $F_{\theta, S}^{e}$ to zero at the expense of having two extra error fields whose statistics are known no better than that of $F_{\theta, S}^{e}$. Besides, the number of degrees of freedom of the interpolation problem in that case almost doubles. In contrast to the $\mathrm{SSH}$, temperature/salinity, and atmospheric forcing controls, whose first moments are supported by climatologies, these degrees of freedom are not supported by real data. That was the major reason why a somewhat artificial correction of the residuals' statistics was chosen.

The main results are summarized as follows.

1. The model fits all the data types within error bars. The greatest discrepancy (18 $\mathrm{cm} \mathrm{rms)} \mathrm{is} \mathrm{observed} \mathrm{with} \mathrm{TOPEX/}$ Poseidon altimetry. The error is especially large in the regions north of $45^{\circ} \mathrm{N}$ and is possibly connected with the deficiencies in the JGM-3 geoid model.

2. Because of relatively large prior errors in surface hydrology, atmospheric flux estimates cannot be significantly improved, at least not in the framework of the simple countergradient closure scheme. As a result, posterior errors for ocean-atmosphere fluxes do not differ significantly from their prior estimates.

3. The optimized circulation pattern exhibits $7 \pm 2 \mathrm{~Sv}$ of deep inflow into the North Pacific Ocean from the south. This figure is $\sim 2$ times larger than that obtained in GCM simulations based on Levitus hydrology. The meridional overturning pattern confirms an overturning cell at $53^{\circ} \mathrm{N}$, which was obtained in the diagnostic GCM computations of Ishizaki [1994].
4. The North Pacific is heated by the atmosphere at a average rate of $11 \pm 7 \mathrm{~W} \mathrm{~m}^{-2}$ and looses $26 \pm 18 \mathrm{~cm}$ of fresh water from its surface per year. Total meridional heat transport in the midlatitudes is statistically undistinguishable from zero.

5. Analysis of the water mass transformation rates reveals the major NPIW formation region east of Hokkaido and South Kuril Islands. A much weaker source site is detected in the Alaska Gyre. The net production rate of the NPIW source water is estimated to be $2.5 \mathrm{~Sv}$.

6. A symmetric algorithm is proposed for estimation of the posterior covariances. It is based on the implicit inversion of the square root of the Hessian matrix.

An interesting byproduct of the error analysis is the posterior correlation matrix. Its components may have some physical sense if we assume that prior errors are entirely caused by natural (Gaussian) variability of the corresponding physical fields. In that case correlations may give an additional knowledge on the dynamically induced teleconnections between the ocean circulation features $\mathscr{L}_{\gamma}$. We have estimated the correlation matrix between all the quantities subjected to error analysis. The computations revealed high $(0.8-0.95)$ correlations between closely spaced features (like Kuroshio transports at $144^{\circ}$ and $\left.160^{\circ} \mathrm{E}\right)$. Much lower correlations $(0.1-0.4)$ have been obtained between the transports of distant current systems. The largest negative value $(-0.27)$ has been observed between the transports of Mindanao and Subarctic currents. Confidence limits of these estimates and their physical background are quite uncertain; therefore it is hard to provide a meaningful interpretation of them until observational evidence is obtained.

In this paper we made an attempt to quantify large-scale circulation by inverting climatological data within the framework of a simple steady state model. The model provided a reasonable fit to all data types with the residual variability timescale of several years. Although the magnitude of the residuals in the $\theta / S$ balance equations was consistent with the error level in parameterization of the subgrid processes (and with our prior hypothesis on $F_{\theta, S}^{e}$ statistics), the residuals still had a considerable impact on the estimates of such delicate quantities as the NP meridional overturning circulation and integral balances of heat and salt. By correcting the residuals' statistics their impact on the integral balances was reduced 3-5 times to $0.03 \mathrm{PW}$ and $0.03 \mathrm{~Sv}$ for the integral budgets of heat and fresh water, respectively. The utilized correction may seem somewhat artificial since there is no direct evidence of the fact that advective property fluxes by large-scale currents balance atmospheric forcing to the precision of $0.03 \mathrm{PW}$ and $0.03 \mathrm{~Sv}$. Apart from the accurate knowledge of the ocean state, such an accuracy requires knowledge of the long-term atmospheric fluxes to the precision of $0.5 \mathrm{~W} \mathrm{~m}^{-2}$ and $2 \mathrm{~cm} \mathrm{yr}^{-1}$, which are much better than the error bars of modern climatologies. Therefore from the viewpoint of formal statistics, accuracy of the data and the model are still unsufficient to derive reliable quantitative estimates of the overturning circulation and property fluxes in the North Pacific. Model accuracy can be increased to some extent by assimilating the data into a high-end GCM, but in that case, rigorous sensitivity studies and error analysis, which were presented here, will be computationally impractical. Besides, most of the modern GCMs still suffer from inadequacy in parameterization of the ocean-atmosphere interaction and deep mixing processes, which appear to be crucial for understanding thermohaline circulation. That is why 
climatological data inversions with simplified dynamics and improved representation of the mixing processes, such as the recently developed parameterizations of the eddy-induced transports [e.g., Gent et al., 1995; McDougall et al., 1996] may be a useful tool in oceanographic data analysis.

\section{Appendix A}

The steady state circulation is described by the following system of equations:

$$
\begin{gathered}
\rho-\mathscr{R}(\theta, S, p)=0, \\
p_{z}+g \rho=0, \\
f(\mathbf{k} \times \mathbf{u})+\frac{1}{\rho_{0}} \nabla p-D_{m} \Delta \mathbf{u}-\left(K_{m} \mathbf{u}_{z}\right)_{z}=0, \\
\nabla \mathbf{u}+w_{z}=0, \\
\nabla(\mathbf{u} \theta)+(w \theta)_{z}-\left(K_{\theta} \theta_{z}\right)_{z}-D_{\theta} \Delta \theta-\hat{\Pi}_{\rho} \theta=F_{\theta}^{e}, \\
\nabla(\mathbf{u} S)+(w S)_{z}-\left(K_{S} S_{z}\right)_{z}-D_{S} \Delta S-\hat{\Pi}_{\rho} S=F_{S}^{e},
\end{gathered}
$$

where $\mathbf{u}$ is the horizontal velocity vector; $w$ is the vertical velocity; $D_{m}, D_{\theta, S}, K_{m}$, and $K_{\theta, S}$ are the horizontal and vertical diffusion coefficients of momentum, potential temperature $\theta$, and salinity $S$, respectively; $f$ is the Coriolis parameter; $g$ is acceleration due to gravity; and $\mathbf{k}$ is the vertical unit vector. $\mathscr{R}$ denotes symbolically the right-hand side of the seawater equation of state [Ishizaki, 1994]. The fields of $F_{\theta}^{e}$ and $F_{S}^{e}$ account for poorly known errors in parameterization of the mixing processes and for temperature and salinity evolution at timescales larger than some prescribed period $T^{*}$. Operator $\hat{\Pi}$ describes the vertical convection processes.

The boundary conditions are the following. At the ocean surface $z=0$ we impose the rigid lid and specify the fluxes of momentum, potential temperature, and salinity:

$$
\begin{gathered}
w=0, \\
p-\rho g \zeta=0, \\
K_{m} \mathbf{u}_{z}-\boldsymbol{\tau}=0, \\
K_{\theta} \theta_{z}-B_{\theta}=0, \\
K_{S} S_{z}-B_{S}=0 .
\end{gathered}
$$

At the ocean bottom the normal flow, potential temperature and salinity fluxes are set to zero.

$$
\begin{gathered}
\left(D_{\theta} \nabla \theta+\mathbf{k} K_{\theta} \theta_{z}\right) \mathbf{n}=0, \\
\left(D_{S} \nabla S+\mathbf{k} K_{S} S_{z}\right) \mathbf{n}=0, \\
\mathbf{u} \nabla H-w-F^{w}=0 .
\end{gathered}
$$

Note that the last condition is not satisfied exactly. The error level $F^{w} \sim 2 \mathrm{~m} \mathrm{yr}^{-1}$ has the order of magnitude of the uncertainty of the Ekman pumping rate into the BBL (section 2).

At the rigid lateral boundaries, tracer fluxes and horizontal velocities are set to zero. Finally, at the open boundaries of the domain we neglect diffusive fluxes of momentum, setting the velocities to be purely geostrophic and to control the values of $\theta$ and $S$, determining them from the data through the inversion algorithm.
The following model for the vertical diffusion coefficients $K_{\theta, S}$ is adopted:

$$
K_{\theta, S}(z)=K_{a}+K^{0} \exp \left[-z^{2} / z_{0}^{2}\right]
$$

The model parameters, which were uncontrolled by the assimilation scheme, are $D_{m}=D_{\theta}=D_{S}=5 \times 10^{6} \mathrm{~cm}^{2} \mathrm{~s}^{-1}, K_{a}=$ $0.3 \mathrm{~cm}^{2} \mathrm{~s}^{-1}, K^{0}=8 \mathrm{~cm}^{2} \mathrm{~s}^{-1}$, and $z_{0}=20 \mathrm{~m}$. Their values were derived from the sensitivity experiments described in section 3 .

Acknowledgments. This study was supported by the Frontier Research system for Global Change through its sponsorship of the International Pacific Research Center (IPRC). Helpful discussions with $\mathrm{H}$. Mitsudera, A. Yaremchuk, and P. Zinin are also acknowledged. This manuscript is contribution $49 / 5227$.

\section{References}

Bateman, H., et al., Higher Transcendental Functions, vol. 2, 396 pp., McGraw-Hill, New York, 1953.

Brasseur, P., A variational inverse method for reconstruction of general circulation fields in the northern Bering Sea, J. Geophys. Res., 96, 4891-4907, 1991.

Bryan, K., Measurements of meridional heat transport by ocean currents, J. Geophys. Res., 67, 3403-3413, 1962.

Bryden, H. L., D. H. Roemmich, and J. A. Church, Ocean heat transport across $24^{\circ} \mathrm{N}$ in the Pacific, Deep Sea Res., Part A, 38, 297-324, 1991.

Cokelet, E. D., and M. L. Schall, ADCP-referenced geostrophic circulation in the Bering Sea, J. Phys. Oceanogr., 26, 1113-1127, 1996.

da Silva, A. M., C. C. Young-Molling, and S. Levitus, Atlas of Surface Marine Data, NOAA Atlas NESDIS, vol. 6, Natl. Oceanogr. Data Cent., Silver Spring, Md., 1995.

Fujio, S., T. Kadowaki, and N. Imasato, World ocean circulation diagnostically derived from hydrographic and wind stress fields, 1 , The velocity field, J. Geophys. Res., 97, 11,163-11,176, 1992.

Fukasawa, M., N. Hagiwara, and Y. Sugimori, Circulation of the North Pacific Intermediate Water, paper presented at Pacific Ocean Remote Sensing Conference 1992, Okinawa, Japan, 1992.

Gent, P. R., J. Willebrand, T. McDougall, and J. C. Mcwilliams, Parameterizing eddy-induced tracer transports in ocean circulation models, J. Phys. Oceanogr., 25, 463-474, 1995.

Gouretski, V. V., and K. Jancke, A description and quality assessment of the historical hydrographic data for the Pacific Ocean, J. Atmos. Oceanic Technol., 16, 1791-1815, 1999.

Grotov, A. S., D. A. Nechaev, G. G. Panteleev, and M. I. Yaremchuk, Large scale circulation in the Bellingshausen and Amunsen Seas as a variational inverse of climatological data, J. Geophys. Res., 103, 13,011-13,022, 1998.

Gunson, J. R., and P. Malanotte-Rizzoli, Assimilation studies of the open ocean flows, 2, Error measures with strongly non-linear dynamics, J. Geophys. Res., 101, 28,473-28,488, 1996.

Harvey, L. D. D., Polar boundary layer plumes and bottom water formation: A missing element in ocean general circulation models, $J$. Geophys. Res., 101, 20,799-20,808, 1996.

Hellerman, S., and M. Rosenstein, Normal monthly wind stress over the world ocean with error estimates, J. Phys. Oceanogr., 13, 10931104, 1983.

Hirst, A. C., D. R. Jackett, and T. J. McDougall, The meridional overturning cells in the world ocean in neutral density coordinates, J. Phys. Oceanogr., 26, 775-791, 1996.

Holloway, G., T. Sou, and M. Eby, Dynamics of circulation of the Japan Sea, J. Mar. Res., 53, 539-569, 1995.

Hurlburt, H. E., A. J. Wallcraft, W. J. Schmitz, P. J. Hogan, and E. J. Metzger, Dynamics of the Kuroshio/Oyashio current system using eddy-resolving models of the North Pacific Ocean, J. Geophys. Res., 101, 941-976, 1996.

Ishizaki, H., A simulation of the abyssal circulation in the North Pacific Ocean, J. Phys. Oceanogr., 24, 1941-1954, 1994.

Kawabe, M., and K. Taira, Flow distribution at $165^{\circ} \mathrm{N}$ in the Pacific Ocean, in Biogeochemical Processes and Ocean Flux in the Western Pacific, edited by M. Sakai and T. Nozaki, Terra Sci., Tokyo, 1995. 
Kawabe, M., and K. Taira, Water masses and properties at $165^{\circ} \mathrm{E}$ in the western Pacific, J. Geophys. Res., 103, 12,941-12,958, 1998.

Lee, T., and J. Marotzke, Inferring meridional mass and heat transports of the Indian Ocean by fitting a general circulation model to climatological data, J. Geophys. Res., 102, 10,585-10,602, 1997.

Lee, T., and J. Marotzke, Seasonal cycles of meridional overturning and heat transport of the Indian Ocean, J. Phys. Oceanogr., 28, 923-943, 1998.

Levitus, S., Climatological Atlas of the world ocean, NOAA Prof. Pap 13, 173 pp., Natl. Oceanic and Atmos. Admin., Silver Spring, Md., 1982.

Levitus, S., and T. P. Boyer, World Ocean Atlas 1994, vol. 4, Temperature, NOAA Atlas NESDIS, vol. 4, Natl. Oceanic and Atmos. Admin., Silver Spring, Md., 1994.

Levitus, S., R. Burgett, and T. P. Boyer, World Ocean Atlas 1994, vol. 3, Salinity, NOAA Atlas Nesdis, vol. 3, Natl. Oceanic and Atmos. Admin., Silver Spring, Md., 1994.

Lukas, R., E. Firing, P. Hacker, P. L. Richardson, C. A. Collins, R. Fine, and R. Gammon, Observations of the Mindanao Current during the Western Equatorial Pacific Ocean Circulation Study, J. Geophys. Res., 96, 7089-7104, 1991.

McBean, G. A., Estimation of the Pacific Ocean meridional heat flux at $35^{\circ} \mathrm{N}$, Atmos. Ocean, 29, 576-595, 1991.

McDougall, T. J., A. C. Hirst, M. H. England, and P. C. McIntosh, Implications of a new eddy parameterization for ocean models, Geophys. Res. Lett., 23, 2085-2088, 1996.

Oberhuber, J. M., An Atlas based on the COADS data set: The budgets of heat, buoyancy and turbulent kinetic energy at the surface of the global ocean, report, 100 pp., Max-Planck-Inst. für Meteorol., Hamburg, Germany, 1988.

Overland, J. E., M. C. Spillane, H. E. Hurlburt, and A. J. Wallcraft, A numerical study of the circulation in the Bering Sea basin and exchange with the North Pacific, J. Phys. Oceanogr., 24, 736-758, 1994.

Reid, J. L., On the total geostrophic circulation in the Pacific Ocean: Flow patterns, tracers and transports, Prog. Oceanogr., 39, 263-352, 1997.

Roemmich, D. H., and T. McCallister, Large scale circulation in the North Pacific Ocean, Prog. Oceanogr., 22, 171-204, 1989.

Schmitz, W. J., Jr., On the interbasin-scale thermohaline circulation, Rev. Geophys., 33, 151-173, 1995.
Sekine, Y., and K. Kutsuwada, Seasonal variation in volume transport of the Kuroshio south of Japan, J. Phys. Oceanogr., 24, 261-272, 1994.

Semtner, A. J., and R. M. Chervin, Ocean general circulation from a global eddy-resolving model, J. Geophys. Res., 97, 5493-5550, 1992.

Stammer, D., C. Wunsch, R. Giering, Q. Zhang, J. Marotzke, and J. Marshall, The global ocean circulation estimated from TOPEX/ Poseidon altimetry and a general circulation model, Rep. 49, Cent. for Global Change Sci., Mass. Inst. of Technol., Cambridge, 1997.

Thacker, W. C., On the role of Hessian matrix in fitting models to data, J. Geophys. Res., 94, 6177-6196, 1989.

Thacker, W. C., and R. B. Long, Fitting dynamics to data, J. Geophys. Res., 93, 1227-1240, 1988.

Toggweiler, J. R., and B. Samuels, On the ocean's large scale circulation near the limit of no vertical mixing, J. Phys. Oceanogr., 28, 1832-1852, 1998.

Van Scoy, K. A., D. B. Olson, and R. A. Fine, Ventilation of North Pacific Intermediate Waters: The role of Alaskan Gyre, J. Geophys. Res., 96, 16,801-16,810, 1991.

Wiffels, S. E., M. M. Hall, T. Joyce, D. J. Torres, P. Hacker, and E. Firing, Multiple deep gyres of the western North Pacific: A WOCE section along $149^{\circ} \mathrm{E}, \mathrm{J}$. Geophys. Res., 103, 12,983-13,009, 1998.

Wu, C. K., J. H. Hu, W. B. Warren, and D. Cutchin, The volume transport of the North Equatorial Current in the western North Pacific between $14^{\circ} \mathrm{N}$ and $20^{\circ} \mathrm{N}$, Acta Oceanogr. Taiwan., 34, 1-16, 1995.

Yaremchuk, M. I., D. A. Nechaev, J. Schröter, and E. Fahrbach, A dynamically consistent analysis of circulation and transports in the southwestern Weddell Sea, Annal. Geophys., 16, 1024-1038, 1998.

Yasuda, I., The origin of the North Pacific Intermediate Water, $J$. Geophys. Res., 102, 893-909, 1997.

$\mathrm{Yu}, \mathrm{L}$., and P. Malanotte-Rizzoli, Inverse modelling of seasonal variations in the North Atlantic Ocean, J. Phys. Oceanogr., 28, 902-922, 1998.

M. I. Yaremchuk, International Pacific Research Center, University of Hawaii at Manoa, Honolulu, HI 96822. (maxy@soest.hawaii.edu)

(Received April 5, 1999; revised May 10, 2000; accepted June 12, 2000.) 